\title{
Terpene-rich Fractions of Ficus Mucoso (Welw) Modulate Lipopolysaccharide-induced Inflammatory Mediators and Aberrant Permeability of the Inner Mitochondrial Membrane in Murine Animal Model
}

Olubukola Oyebode ( $\nabla$ bukioyebode@gmail.com )

University of Ibadan College of Medicine https://orcid.org/0000-0002-5323-3743

John Oludele Olanlokun

University of Ibadan College of Medicine

Olamilekan Salami

University of Ibadan College of Medicine

Ifeanyi Obi

University of Ibadan College of Medicine

Olusola Bodede

University of South Africa - Florida Campus: University of South Africa - Science Campus

Gerhard Prinsloo

University of South Africa - Florida Campus: University of South Africa - Science Campus

Olufunso Olorunsogo

University of Ibadan College of Medicine

\section{Research Article}

Keywords: mitochondrial swelling, inflammation, lipopolysaccharide, pro-inflammatory cytokines

Posted Date: July 27th, 2021

DOI: https://doi.org/10.21203/rs.3.rs-722445/v1

License: (c) (1) This work is licensed under a Creative Commons Attribution 4.0 International License.

Read Full License

Version of Record: A version of this preprint was published at Inflammopharmacology on October 6th, 2021. See the published version at https://doi.org/10.1007/s10787-021-00876-x. 


\section{Abstract}

Ficus mucoso is traditionally used to treat various infections. This study compared the efficacy of terpene-rich fractions of $F$. mucoso root bark on LPS-induced inflammation, liver mitochondrial permeability transition (mPT) pore, an index of mitochondrial health, and associated pathological alterations. Terpene-Rich fractions of Dichloromethane (TRDF) and Ethylacetate fractions of F. mucoso (TREF) were obtained according to the method described by Ferguson (1956). A single intraperitoneal injection of $1 \mathrm{mg} / \mathrm{kg}$ lipopolysaccharide (LPS) were given to mice to induce systemic inflammation for $72 \mathrm{hrs}$. Evaluation of the effects of the TRDF and TREF on levels of pro-inflammatory mediators (TNF-a, $\mathrm{IL}-1 \beta, \mathrm{IL}-6)$ and antioxidant indices against LPS-induced hepatic damage were carried out. Mitochondrial swelling was monitored spectrophotometrically as well as mitochondrial ATPase activity and lipid peroxidation.

This study reveals that TRDF and TREF possess anti-inflammatory potentials which is related to reduction in levels of pro-inflammatory cytokines, restoration of antioxidant status, reduction in levels of liver marker enzymes as well as associated pathological injury. Furthermore, LPS caused induction of opening of the liver mPT pore which was significantly inhibited by TRDF at 100 and $200 \mathrm{mg} / \mathrm{kg}$ bw by $71 \%$ and $88 \%$ respectively, but only at $100 \mathrm{mg} / \mathrm{kg}$ TREF. Furthermore, mitochondrial ATPase activity was inhibited largely by TRDF. The UPLC-ESI-MS analysis revealed the presence of terpenoid derivatives and a few aromatic metabolites in TRDF. The terpene dominance of TRDF metabolites was further justified on the ${ }^{1} \mathrm{H}$ NMR fingerprint.

Overall, TRDF is more effective as a cocktail of anti-inflammatory compounds than TREF against LPSinduced acute systemic inflammation.

\section{Introduction}

The etiology of many diseases stems from inflammation. This constitutes a global health concern (Glass et al., 2010; Furman et al., 2019).Although, inflammation regulates defense against infection and promotes repair to prevent further tissue damage, persistent inflammatory process usually drives the onset of a number of disorders arising from various cellular alterations and metabolic interactions that eventually sustain and worsen tissue damage (Medzhitov, 2008; Chen et al., 2017

Recent scientific findings reveal that mitochondria are involved in the regulation of innate immunity and are also drivers of inflammatory responses (Mohanty et al., 2019; Missiroli et al., 2020). Mitochondrial ROS has been shown to play a significant role in this regard (Rimessi et al., 2016). The mitochondrial permeability Transition ( $\mathrm{MPT}$ ) pore opening has been shown to occur in many disease conditions including inflammation (Crompton, 1999; Crouser et al., 2004; Oyebode et al., 2019). The opening of the $\mathrm{mPT}$ pore is activated by a number of factors including excessive ranges of calcium, inorganic phosphate and oxidative stress (Halestrap et al., 2004; Halestrap and Richardson, 2015) which results in matrix swelling, enhancement of ATPase activity, Mitochondrial Outer Membrane Permeabilization 
(MOMP) (Crompton et al., 1999; Bauer and Murphy, 2020). On the other hand, pharmacological inhibitors of the pore or mPT pore sealing agents ( e.g cyclosporine A, spermine) have been reported to preserve mitochondrial function in many diseases that stems from inappropriate opening of the pore (Najafi et al., 2014; Salimi et al., 2019; Oyebode et al., 2020). Interestingly several medicinal plants have also exhibited modulatory effects on the mPT pore under different conditions (Oyebode et al., 2017; Olanlokun et al., 2018; Olowofolahan et al., 2020).

It is now documented that prolonged of scores of anti-inflammatory drugs have damaging effects on critical organs as well as on isolated mitochondria (Battaglia et al., 2005; Pourahmad, et al., 2011; PereiraLeite et al., 2016; Salimi et al., 2019). Hence, the search for safe/secure anti-inflammatory agents is on the rise. Natural products had been a source of anti-inflammatory compounds (Abarca-Vargas and Petricevich, 2019) with terpenes taking the credit for anti-inflammatory effects alongside different pharmacological roles. Ficus mucoso stems from the family of Moraceae comprising numerous species of trees and shrubs extensively dispensed in tropical and subtropical countries (Corner, 1962; Rahman and Khanom, 2013). The stem bark of Ficus mucoso is traditionally used to treat bronchial infections (Bouquet 1969). Although F. mucoso is known to possess anti-inflammatory potential, there is paucity of facts on the mechanism of its anti-inflammatory action in the public domain. Given that mitochondria play a pivotal role in the regulation of inflammatory responses and that terpenes had been proven to be found in F. mucoso, the mechanistic effects of the anti-inflammatory effects of terpene-abundant fractions in addition to their mitochondrial-protective potentials in LPS-driven inflammation were evaluated.

\section{Material And Methods}

\subsection{Collection and extraction of plant material}

The roots of $F$. mucoso were freshly harvested and obtained from Oje market, Ibadan, Oyo State, Nigeria. Identification and authentication of samples were carried out at the Department of Botany, University of Ibadan and a specimen voucher number (UIH-22946) was deposited in the Herbarium. The whole roots were washed in clean water, Thereafter which the bark were peeled and air-dried for a couple of weeks in the laboratory. Thereafter, they were milled into a fine powder and weighed. Milled root bark of $F$. mucoso $(2.3 \mathrm{~kg})$ was submerged with enough methanol $(100 \%)$ in glass jars at room temperature for $72 \mathrm{~h}$. The flasks were stoppered and left to stand for $72 \mathrm{hrs}$. The extracts were then filtered using Whatman No 1 filter paper after which the filtrate (crude methanol extract of $F$. mucoso) was concentrated using a rotary evaporator at $40^{\circ} \mathrm{C}$. The resulting filtrate was lyophilized to obtain a powdery form that could be easily weighed.

\subsection{Partitioning of crude Methanol Extract of $F$. mucoso (MEFM) using Vacuum Liquid Chromatography (VLC)}

Silica gel 60 (0.040-0.063 mm, MERCK), $20 \mathrm{~g}$ was adsorbed to MEFM (10g). A sintered funnel for Vacuum Liquid Chromatography (VLC) was packed with $20 \mathrm{~g}$ Silica gel (Hopkins and Williams, England). 
In order to de-fat the sample, n-hexane was first added while fractions were collected in order of increasing polarity using dichloromethane, ethylacetate and methanol. The sequentially-eluted fractions were concentrated using a rotary evaporator under reduced pressure to obtain concentrated solvent-free fractions, dichloromethane, ethylacetate, and methanol fractions of the plant. Given that terpenes are non-polar, dichloromethane and ethylacetate free solvent fractions were exhaustively washed with petroleum ether according to the method described by Fergusson (1956) to obtain Terpene-Rich Dichloromethane fraction (TRDF) and Terpene-Rich Ethylacetate fractions of $F$. mucoso (TREF) root bark. These fractions were stored in glass sample bottles and kept in the refrigerator until use.

\subsection{Detection of terpenes by Thin layer chromatography (TLC)}

The crude fractions of dichloromethane (DFFM) and ethylacetate fractions (EFFM) as well as their terpene-rich fractions (TRDF and TREF) were tested for the presence of terpenes via thin layer chromatography. It was carried out by using TLC aluminum sheets of pre-coated silica gel using the solvent system comprising hexane/ethyl acetate (1:1). Samples were prepared by diluting the fractions with respective solvent and then applied $1-10 \mu$ lo a TLC plate using capillary tubes. The spotted plate was placed in the TLC glass chamber (solvent saturated) for development of the chromatogram. The plates were then air dried and spots on TLC were visualized by spraying with $10 \%$ vanillin-sulphuric acid in methanol, followed by heating at $110^{\circ} \mathrm{C}$ for $1-2$ minutes.

\subsection{Metabolite profiling of terpene-rich fractions of $F$. mucoso}

In order to obtain a profile of metabolies, the TRDF and TREF were characterized using a Waters UPLC coupled in sequence to Waters SYNAPT TM ${ }^{\mathrm{T}}$ HDMS $^{\mathrm{TM}}$ system (Waters Corporation, MA, USA). An optimized chromatographic separation was obtained on Waters UPLC utilizing a Waters HSS T3 C18 column $(150 \mathrm{~mm} \times 2.1 \mathrm{~mm}, 1.8 \mu \mathrm{m})$, temperature controlled at $60^{\circ} \mathrm{C}$ and a binary solvent mixture of water (Eluent $\mathrm{A}$ ) and acetonitrile (Eluent $\mathrm{B}$ ) both containing $10 \mathrm{mM}$ formic acid ( $\mathrm{pH}$ of water adjusted to 2.4) was used. The initial conditions were $98 \% A$ at a flow rate of $0.4 \mathrm{~mL} / \mathrm{min}$, maintained for 1 minute, followed by a linear gradient to $2 \% \mathrm{~A}$ at 16 minutes. First, the conditions were kept constant for 1 minute and afterwards changed to the initial conditions. The runtime was 20 minutes while the injection volume was $2 \mu \mathrm{L}$. The samples were then maintained at $8^{\circ} \mathrm{C}$ in the Waters Sample Manager during the analysis.

The SYNAPT G1 mass spectrometer, used in V-optics and operated in electrospray mode allowed detection of all compounds compactible with electrospray ionization (ESI). Leucine enkephalin (50 $\mathrm{pg} / \mathrm{mL}$ ) was used as reference calibrant to obtain typical mass accuracies between 1 and $5 \mathrm{mDalton}$ $(\mathrm{mDa})$. Both ESI positive and negative modes were obtained from the mass spectrometer (capillary voltage of $2.5 \mathrm{kV}$, sampling cone at $30 \mathrm{~V}$, extraction cone at $4.5 \mathrm{~V}$ ). The scan time was 0.1 seconds covering the 50 - 1000 Dalton mass range with an interscan time of 0.02 seconds. The source temperature was $120^{\circ} \mathrm{C}$ while desolvation temperature was set at $450^{\circ} \mathrm{C}$. Nitrogen gas was used as the 
nebulization gas at a flow rate of $550 \mathrm{~L} / \mathrm{h}$ and cone gas was added at $50 \mathrm{~L} / \mathrm{h}$. The massLynx 4.1 (SCN 872) software was employed to control the hyphenated system and to process the data.Identification of compounds was further enhanced by analysing all samples with both low and high collision energy settings of the collision cell. To reduce compound fragmentation, a low energy setting of $3 \mathrm{eV}$ was used, while a collision energy ramp of $10-40 \mathrm{eV}$ was used to enhance fragmentation of molecules. Argon was used as the collision gas employed in the collision cell was argon. Additional characterization of the TRDF was carried out by ${ }^{1} \mathrm{H}$ Nuclear Magnetic Resonance (NMR) fingerprinting. The choice of TRDF was based on its improved pharmacological effect/terpene dominance compared to TREF. The NMR spectrum was recorded using deuterated chloroform ( $\left.\mathrm{CDCl}_{3}\right)$ (Merck, Darmstadt, Germany) at room temperature on an Agilent ProPulse $500 \mathrm{MHz}$ spectrophotometer (USA). The ${ }^{1} \mathrm{H}$ NMR data was processed using MestReNova software Version 14.2.0-26256 (Mestrelab Research S.L. (USA).

\subsection{Chemicals and reagents}

Lipopolysaccharide (Escherichia coli serotype 0111:B4) was procured from AK Scientific, China. Calcium, trichloroacetic acid (TCA) Tris-HCl, bovine serum albumin (BSA), sodium dodecyl sulphate (SDS), Folin-Ciolcalteau, spermine, mannitol, sucrose, sodium succinate and rotenone and all other chemicals were obtained from Sigma Chemical Co., (St. Louis, MO, USA). All solvents used are of high analytical grade.

\subsection{Animal grouping and experimental design}

\subsubsection{Experimental animals}

Male Swiss albino mice $(15 \mathrm{~g})$ were obtained from the Veterinary Medicine Animal House, University of Ibadan, Nigeria. The animals were acclimatized for a couple of weeks in the Animal House, Department of Biochemistry, University of Ibadan, Ibadan, Nigeria. They were given water and rat chow without restriction. They were kept under standard conditions of temperature and 12-h dark/light cycle.

\subsubsection{Experimental design}

\subsubsection{Determination of LPS dose induction}

In order to determine the suitable dose of LPS in the strain of mice, two doses $(0.5 \mathrm{mg} / \mathrm{kg}, 1.0 \mathrm{mg} / \mathrm{kg})$ of LPS were intraperitoneally administered to mice for 3 days $(72 \mathrm{hrs})$ in a pilot study after which they were sacrificed by cervical dislocation.

\subsubsection{Induction of Inflammation/ treatment}

To evaluate the protective effect of terpene-rich fractions of $F$. mucoso (TRDF and TREF) on LPS-induced damage, eighty mice were randomly distributed into ten (10) groups of eight (8) animals each. LPS was dissolved in normal saline which served as the vehicle and was also administered to control mice. The groups were as follow: 
Group 1: Normal control (normal saline); Group 2: LPS only (1 mg/kg)

Group 3: TRDF (100 mg/kg); Group 4: TRDF $(200 \mathrm{mg} / \mathrm{kg})$

Group 5: LPS + TRDF (100 mg/kg); Group 6: LPS + TRDF (200 mg/kg)

Group 7: TREF (100 mg/kg); Group 8: TREF $(200 \mathrm{mg} / \mathrm{kg})$

Group 9: LPS + TREF (100 mg/kg); Group 10: LPS + TREF (200 mg/kg)

Mice were initially challenged with LPS for first 3 days in groups 5, 6, 9 and 10 after which they were treated with different doses of TRDF and TREF or fractions alone (without LPS) for the last 3 days before the termination of the experiment. LPS was dissolved in normal saline ( $0.9 \% \mathrm{NaCl}$ solution).

\subsubsection{Estimation of pro-inflammatory cytokines}

Whole blood samples were drawn into plain tubes and allowed to clot for $2 \mathrm{hrs}$ at room temperature after which they were centrifuged at 3,000 rpm for 15 minutes at $4^{\circ} \mathrm{C}$. The clear supernatants were stored as serum. Serum samples exposed to LPS and/or treated with or without TRDF and TREM were used to evaluate TNF-a, IL-1 $\beta$, and IL- 6 levels. These cytokines were evaluated using Elabscience (CA, USA) standard ELISA kits according to the manufacturer's instructions. The results were calculated based on the absorbance levels of complex-cytokine-antibodies, and the units of cytokines were described as $\mathrm{pg} / \mathrm{ml}$.

\subsubsection{Quantification of catalase and superoxide antioxidant activity}

The post mitochondrial fraction was kept for estimation of antioxidant activity. Catalase (CAT; EC 1.11.1.6) activity was determined by a procedure described by Aebi [1984]. The reaction mixture containing $1.8 \mathrm{~mL}$ potassium phosphate buffer $(\mathrm{pH} 7.0), 180 \mathrm{~mL}$ of $300 \mathrm{mM} \mathrm{H}_{2} \mathrm{O}_{2}$, and $20 \mathrm{~mL}$ of sample (1: 50 dilution) was carried out by monitoring the clearance of $\mathrm{H}_{2} \mathrm{O}_{2}$ at $240 \mathrm{~nm}$ at $25^{\circ} \mathrm{C}$. The decrease in $\mathrm{H}_{2} \mathrm{O}_{2}$ was monitored for 2 minutes (10s intervals), at 240nm using a UV-visible spectrophotometer (Shimadzu) and expressed as $\mathrm{mmol}$ of $\mathrm{H}_{2} \mathrm{O}_{2}$ consumed $/ \mathrm{min} / \mathrm{mg}$ of protein. The method of Misra and Fridovich (1972) was employed in the determination of superoxide dismutase (SOD) activity. The ability of SOD to inhibit the autooxidation of epinephrine $(\mathrm{pH} 10.2)$ is the basis for the simple assay for SOD. The reaction mixture containing $50 \mu \mathrm{l}$ of sample was added to $2.5 \mathrm{ml}$ of $0.05 \mathrm{M}$ carbonate buffer $(\mathrm{pH} 10.2)$ and $0.3 \mathrm{ml}$ of ephinephrine, mixed by inversion in a cuvette while change in absorbance was monitored every 30 seconds for 2.5 minutes at $480 \mathrm{~nm}$.

\subsubsection{Evaluation of histopathology of liver and serum biomarkers}

The livers excised from mice were fixed in $10 \%$ formalin and were processed to paraffin blocks, sectioned $(5 \mu \mathrm{m})$ and stained with hematoxylin-eosin (H\&E) for histological analysis. These were counter stained in $10 \%$ aqueous eosin, incubated and mounted for photomicrography. Alanine Aminotransferase (ALT) and 
Aspartate Aminotransferase (AST) activities were measured by monitoring the concentration of pyruvate hydrazone formed according to the method described by Reitman and Frankel (1957). Levels of serum ALT and AST were determined using standard kits supplied by Fortress Diagnostic Limited (UK).

\subsubsection{Isolation of low strength ionic rat liver mitochondria}

Rat liver mitochondria were isolated according to the method described by Johnson and Lardy (1967). The animals were sacrificed by cervical dislocation, dissected and the tissues of interest were immediately excised. The liver was washed several times in isolation buffer ( $210 \mathrm{mM}$ Mannitol, $70 \mathrm{mM}$ Sucrose, $5 \mathrm{mM}$ HEPES and $1 \mathrm{mM}$ EGTA at pH 7.4) to hav a blood-free tissue. A $10 \%$ suspension was prepared by homogenizing the weighed and minced liver in a Teflon-glass cup homogenizer. The suspended tissue in isolation buffer was implored into a refrigerated Sigma (3e30 K, Germany) centrifuge, where the nuclear fraction and cell debris were sedimented by low speed centrifugation twice at 2,300 rpm for 5 minutes. The supernatant was spun at 13,000 rpm for $10 \mathrm{~min}$ to pellet the mitochondria (the rate limiting step). The mitochondria (pellet) obtained after the supernatant was discarded was washed to remove impurities by re-suspending in washing buffer ( $210 \mathrm{mM}$ Mannitol, $70 \mathrm{mM}$ Sucrose, $5 \mathrm{mM}$ HEPES and 50\% BSA at pH 7.4) and centrifuged at 12,000 rpm for 10 minutes. This washing stage was done twice. The mitochondria were immediately suspended in a solution of ice-cold MSH Buffer (Mannitol, Sucrose, HEPES-KOH, pH 7.4), then dispensed in Eppendorf tubes in aliquots and placed on ice for immediate use.In order to preserve the integrity of the mitochondria, temperature was maintained at $4^{0} \mathrm{C}$ throughout the entire process.

\subsubsection{Measurement of mitochondrial swelling}

Mitochondrial swelling was determined according to the method described by Lapidus and Sokolove (1992). Uncoupled mitochondria $(0.4 \mathrm{mg} / \mathrm{ml})$ were incubated in the presence of $0.8 \mu \mathrm{M}$ rotenone and MSH buffer for 3.5 minutes prior to the addition of $5 \mathrm{mM}$ sodium succinate, the respiratory substrate. In order to assess $\mathrm{Ca}^{2+}$-induced swelling, mitochondria were pre-incubated in $0.8 \mu \mathrm{M}$ rotenone and MSH buffer for 3 minutes. $\mathrm{Ca}^{2+}$ was then added to the reaction mixture while sodium succinate was added 30 seconds later in a total reaction volume of $2.5 \mathrm{ml}$. Spermine was used as the standard inhibitor of mitochondrial swelling, and was added prior to mitochondrial pre-incubation with rotenone. Change in absorbance was estimated at $540 \mathrm{~nm}$ at 30 seconds interval for 12 minutes in a T70 UV-visible spectrophotometer (PG Instrument Ltd). Mitochondrial swelling was measured as decrease in absorbance at 540nm.

Permeability transition in the mitochondria isolated from the treated groups was carried out on the same mitochondrial protein content from the control group and the absorbance monitored accordingly. The mitochondrial protein was determined by the method of Lowry et al. (1951) using bovine serum albumin as standard.

\subsubsection{Assay for Mitochondrial FoF1 ATPase (mATPase) Activity}

The mATPase activity was determined as described by Olorunsogo and Malomo (1985). The reaction mixture comprises $65 \mathrm{mM}$ Tris-HCl buffer $\mathrm{pH} 7.4,0.5 \mathrm{mM} \mathrm{KCl}, 1 \mathrm{mM}$ ATP and $25 \mathrm{mM}$ sucrose (pH 7.4) with 
a total volume of $2 \mathrm{ml}$. The reaction was initiated by the addition of a mitochondria (of known protein) and was allowed to proceed in a shaker water bath for 30 minutes at $27^{\circ} \mathrm{C}$. The reaction was stopped by the addition of $1 \mathrm{ml}$ of a $10 \%$ of sodium dodecyl sulphate (SDS) and $1 \mathrm{ml}$ of the resulting mixture was kept for phosphate determination. The zero time tube was prepared by addition of ATP to the reaction vessel with immediate addition of SDS, but for 30 seconds intervals for other reaction vessels.

\subsubsection{Estimation of inorganic phosphate}

The concentration of inorganic phosphate released from ATP hydrolysis was measured according to the procedure described by Bassir (1963) and as modified by Olorunsogo et al. (1979).

\subsubsection{Determination of mitochondrial lipid peroxidation (in vivo)}

Mitochondrial lipid peroxides were estimated by measuring the formation of thiobarbituric aid reactive substances (TBARS) present in the mitochondria, based on the reaction between 2-thiobarbituric acid (TBA) and malondialdehyde (MDA), an end product of lipid peroxides according to the method described by Varshney and Kale (1990). An aliquot of $0.4 \mathrm{ml}$ of test sample (mitochondria) was mixed with $1.6 \mathrm{ml}$ of Tris-KCL buffer to which $0.5 \mathrm{ml}$ of $30 \%$ TCA was added. Then $0.5 \mathrm{ml}$ of $0.75 \%$ TBA was added and placed in a water bath for 45 minutes at $80^{\circ} \mathrm{C}$. This was immediately cooled on ice to room temperature and centrifuged at 3,000 rpm for 10 minutes. The absorbance of the supernatant was measured against a reference blank of distilled water at $532 \mathrm{~nm}$. The concentration of TBARS was calculated using extinction co-efficient of $0.156 / \mu \mathrm{M} / \mathrm{cm}$ (Adam - Vizi and Seregi, 1982).

\section{Lipid peroxidation (nmole TBARS/mg protein) $=$ Absorbance $\times$ volume of mixture}

$\mathrm{E} 532 \mathrm{~nm} \times$ volume of sample $\times \mathrm{mg}$ protein $/ \mathrm{ml}$

\subsubsection{Statistical analysis}

Using one-way ANOVA analysis of variance followed by Tukey's test, multiple comparisons were made after analysis by using GraphPad Prism 6.0 (GraphPad Software, San Diego, CA, USA) . All the values were expressed in mean \pm standard deviation (SD) and differences were considered significant at $p<$ 0.05 .

\section{Results}

\subsection{Effects of varying doses of LPS administration on serum pro-inflammatory cytokines, antioxidant enzymes and aminotransferase activities in mice}

In order to determine the dose of LPS suitable for induction of inflammation in the mice strain, intraperitoneal administration of two doses $(0.5,1.0 \mathrm{mg} / \mathrm{kg})$ of LPS was tested alongside a control group that received normal saline alone. Our results revealed that levels of serum pro-inflammatory cytokines - 
TNF- $a$, IL-1 $\beta$ and IL- 6 in animals that received LPS increased significantly $(p<0.05 ; p<0.01)$ when compared to control (Figure 1a, b, c). Similarly, there were marked increase in levels of serum aspartate and alanine aminotransferases in LPS-administered animals with respect to control (Figure 1f). However, LPS-treated mice had significant $(p<0.05)$ decreases in activities of the antioxidant enzymes (SOD and catalase) when compared to control (Figure 1d, e).

\subsection{Effects of LPS on mice liver mitochondrial Permeability Transition pore}

Figure 2 shows the representative profile of changes in absorbance over a period of 12 minutes of mitochondria isolated from mice previously intraperitoneally administered doses $(0.5,1.0 \mathrm{mg} / \mathrm{kg})$ of LPS for 3 days. First, swelling of mitochondria isolated from control mice was determined. The data presented indicate that over a period of twelve minutes there was no significant change in the absorbance of mitochondria isolated from the control mice in the presence of succinate, the respiratory substrate. However, on the addition of calcium, there was a large amplitude swelling and the MPT pore was opened by 5.1 folds compared to control (no calcium). Interestingly, the calcium-induced swelling of the pore was almost completely reversed $(90 \%)$ by spermine (a standard inhibitor). Furthermore, the data clearly show that the MPT pore of mitochondria isolated from LPS-treated mice was significantly opened. In this regard, induction of pore opening of 4.0 and 4.9 folds were observed in livers of mice intraperitoneally administered 0.5 and $1.0 \mathrm{mg} / \mathrm{kg}$ LPS. The higher dose of $1 \mathrm{mg} / \mathrm{kg}$ LPS was selected for further study because it gave a higher inductive effect in vivo

\subsection{TLC profiling of the terpene-rich fractions of $F$. mucoso (TRDF \& TREF)}

Figure 3 shows the TLC plate of terpene-rich fractions of F. mucoso (TRDF and TREF). Different chromogenic reagents give distinct colours for the specific phytochemical. A purple colour against a white background when sprayed with Vanillin-sulphuric acid (10\%) indicates the presence of terpenes. The plate therefore indicates that terpenes are present in TRDF and TREF. It further shows that terpenes are more abundant in TRDF relative to TREF.

\subsection{Effects of terpene-rich fractions of $F$. mucoso in LPS-induced inflammation, alteration in antioxidant status and elevation in hepatic enzyme activities}

As shown in figure 4, LPS-induced mice exhibited higher levels of serum TNF-a, IL-1 $\beta$ and IL- 6 when compared with normal mice while administration of TRDF and TREF $(100 \mathrm{mg} / \mathrm{kg}$ and $200 \mathrm{mg} / \mathrm{kg}$ per day) without LPS treatment maintained basal levels of the pro-inflammatory cytokines. Interestingly, coadministration of TRDF and TREF in LPS-treated mice significantly $(p<0.05)$ reduced serum levels of TNF- $a$, IL-1 $\beta$, and IL- 6 . However, the terpene-rich dichloromethane fraction (TRDF) produced a greater effect in a dose-dependent manner in reducing elevated levels of pro-inflammatory cytokines in LPSinduced mice.

Similarly, mice treated with doses of terpene-rich fractions (TRDF and TREF) in the absence of LPS administration preserved activities of antioxidant enzymes-CAT and SOD to varying extent with respect to 
the control while LPS-induced reduction in CAT and SOD activities were restored by doses of TRDF and TREF in a dose-independent manner.

Again, elevated levels of serum AST and ALT in LPS-treated mice were significantly reduced by administration of TRDF (100 mg/kg and $200 \mathrm{mg} / \mathrm{kg}$ per day) while administration of TRDF alone had no significant effect on the activities of the enzymes when compared with control. Contrarily, administration of TREF alone brought about a significant elevation in the levels of the liver marker enzymes relative to control. This effect was more pronounced at the higher dose $(200 \mathrm{mg} / \mathrm{kg} \mathrm{bw})$. Furthermore, when TREF (100 mg/kg and $200 \mathrm{mg} / \mathrm{kg}$ per day) were co-administered with LPS-induced mice, the lower dose (100 $\mathrm{mg} / \mathrm{kg} \mathrm{bw}$ ) exhibited a reduction in serum levels of ALT and AST when compared with LPS-induced mice while the higher dose $(200 \mathrm{mg} / \mathrm{kg}$ bw) had no significant effect whatsoever.

\subsection{Histological evaluation of the liver in TRDF and TREF-treated rats with LPS-induced inflammation}

The morphological alterations of the livers observed by H \& E staining was carried out in LPS-induced mice following treatment with TRDF and TREF (figure 5). The histological evaluation of control livers showed normal architecture without pathological signs. Livers of mice treated with TRDF (without LPS exposure) exhibited normal central venule and moderately congested portal vein. However, administration of TREF alone caused extensive area of ground glass appearance and focal area of lymphoid aggregates in the liver. The livers of LPS- treated mice show marked to severe disseminated micro/macro vesicular steatosis and marked periportal infiltration by inflammatory cells. Interestingly, exposure of LPS pretreated mice to TRDF (100 mg/kg and $200 \mathrm{mg} / \mathrm{kg}$ per day) significantly recovered damaged hepatocytes in contrast to TREF. However, the lower dose of TREF $(100 \mathrm{mg} / \mathrm{kg} \mathrm{bw})$ had a mild protective effect on LPSinduced liver inflammation while the higher dose $(200 \mathrm{mg} / \mathrm{kg})$ TREF had no significant effect on LPSinduced liver injury.

\subsection{Effects of Terpene-rich fractions of $F$. mucoso on liver mitochondrial permeability transition pore in LPS-induced inflammation}

Figure 6 is a representative profile of changes in absorbance of mitochondria isolated from normal, LPSinduced mice and those treated with TRDF and TREF after being challenged with LPS. The data obtained reveal that control mice had intact inner mitochondrial membrane as shown by an insignificant change in absorbance at $540 \mathrm{~nm}$. Similarly, administration of doses of TRDF (in the absence of LPS) had no effect whatsoever on the mPT pore. However, administration of TREF alone at $100 \mathrm{mg} / \mathrm{kg}$ and $200 \mathrm{mg} / \mathrm{kg}$ activated opening of the MPT pore by 1.1 and 2.4 folds, respectively. LPS administration significantly induced opening of the pore by 3.3 folds at $1 \mathrm{mg} / \mathrm{kg}$ LPS and the rate of mitochondrial swelling demonstrated by LPS was comparable to that of calcium (3.6 folds), the standard triggering agent of the $\mathrm{mPT}$ pore. Interestingly, mitochondrial swelling induced by LPS was significantly inhibited in the presence of TRDF $(100 \mathrm{mg} / \mathrm{kg} ; 200 \mathrm{mg} / \mathrm{kg})$ and low dose of TREF $(100 \mathrm{mg} / \mathrm{kg})$ by 71,88 and $67 \%$ respectively while spermine, the standard pore inhibitor has an inhibitory effect of $64 \%$. In contrast, the high dose of TREF induced opening of the pore by 5.2 folds. 


\subsection{Effect of terpenes from $F$. mucoso on liver mitochondrial ATPase activity and lipid peroxidation in LPS-induced mice}

To further monitor mitochondrial health with respect to its ATP generating function, the investigation of the mitochondrial ATPase (mATPase) activity and degree of lipid peroxidation of livers of mice previously exposed to TRDF and TREF in LPS-treated mice were carried out (figure 7). There results showed that there was significant enhancement of mitochondrial ATPase activity (increased levels of inorganic phosphate) at physiological pH in LPS-induced mice compared to the control which was close to 2,4-DNP, a standard uncoupler of oxidative phosphorylation. It was observed that the consumption of TRDF (100 \& 200mg/kg bw) without LPS-challenge maintained basal levels of mATPase activity while co-administration in LPS-induced mice significantly inhibited LPS-induced elevation of inorganic phosphate levels. A significant induction of mATPase activity was observed in LPS-treated mice coadministered with TREF $(200 \mathrm{mg} / \mathrm{kg})$ relative to the control. The lower dose of TREF $(100 \mathrm{mg} / \mathrm{kg}) \mathrm{had}$ a marginal inhibitory effect of mATPase activity. Furthermore, thiobarbituric acid reactive substances (TBARS) content of liver mitochondria were significantly elevated in LPS-challenged mice with statistical significance in comparison to the control group. Interestingly, treatment of LPS-induced mice with doses of TRDF and TREF significantly $(p<0.05)$ inhibited LPS-induced increase in mitochondrial peroxides to varying extents.

\subsection{Profile of TRDF and TREF metabolites}

Compounds matching the chromatographic peaks in TRDF and TREF of F. mucoso (Figure 8 \& 9 , respectively) were determined by full-scan MS and MS/MS analysis using both positive and negative-ion mode based on their accurate mass, and fragment ions in comparison with those available on databases like MassBank and SciFinder ${ }^{\circledR}$ including data reported in literature. Twelve compounds each were identified in the TRDF and TREF of the F. mucoso extract with detailed reports of the compounds presented in Tables 1 and 2, respectively. These compounds comprise derivatives of mono-, sesqui-, di-, sester- and triterpenes. Some aromatic compounds, much of which occurred in TREF were also identified. Compounds common to both fractions are loliolide and azelaic acid. Two nitrogen-containing compounds (nonanamide and nopalinic acid) were found only in TRDF.

The full and regions-expanded ${ }^{1} \mathrm{H}$ NMR spectra of TRDF is presented in Figure 10 with chemical shifts of compounds ranging from 0.54 to $9.77 \mathrm{ppm}$. The full spectrum revealed a dense upfield region and a less dense to very low intensity downfield region.

\section{Discussion}

A causal connection between mitochondrial illness and organ damage is fast gaining acceptance as a new concept for the etiology of inflammation-induced organ dysfunction (Brealey et al., 2002; Supinski et al., 2020). The intraperitoneal administration of lipopolysaccharide (LPS) is an experimental model for inducing systemic and hepatic inflammation in rodents (Hamesch et al., 2015). Oxidative stress and 
release of pro-inflammatory cytokines has been shown to be a well- known mechanism of LPS-induced hepatic injury (Hamesch et al., 2015; Liu et al., 2017).

Superoxide dismutase (SOD), an important antioxidant enzyme, catalyzes the dis-mutation of the superoxide anion $\left(\mathrm{O}_{2}\right.$.-) into hydrogen peroxide and molecular oxygen (Magnani et al., 2000). Given that hydrogen peroxide is highly deleterious to the cell, the decomposition of hydrogen peroxide $\left(\mathrm{H}_{2} \mathrm{O}_{2}\right)$ to water and oxygen is brought about by another antioxidant enzyme, catalase. This study compared the therapeutic effects of terpene-rich fractions of F. mucoso on LPS-induced alteration in hepatic mitochondrial permeability transition, oxidative stress and inflammatory mediators in mice. First, the suitable dose of LPS for hepatic inflammation in the mice strain was determined in a pilot study. The observation that administration of doses of LPS brought about a rise in levels of key pro-inflammatory mediators (TNF-a, IL-1 $\beta$ and IL-6) which was consistent with increased activities of the serum liver marker enzymes (AST \& ALT) and decreased antioxidant enzyme activities (SOD \& CAT) in the postmitochondrial fraction indicate that hepatic inflammation has been induced in the challenged mice. Furthermore, findings that doses of LPS promoted large amplitude matrix swelling in a dose-dependentmanner is an attestation to the earlier reported role of mitochondria in inflammation (Missiroli et al., 2020). In addition, the inductive effect of LPS on liver MPT pore is in tandem with the reports of Crouser et al., (2004) that mitochondrial dysfunction results from alteration in permeability of liver mitochondrial membranes during acute endotoxemia. Taken together, these data suggest that induction of hepatic inflammation occurred via production of cytokines, overwhelming antioxidant capacity possibly through generation of oxidant species and activation of $\mathrm{MPT}$ pore opening. Given the pronounced effects observed at the higher dose, $1 \mathrm{mg} / \mathrm{kg}$ LPS was adopted for the main study.

The presence of terpenes in F. mucoso as revealed by the TLC profile of terpene- rich fractions (TRDF and TREF) is in consonance with the findings of Djemgou et al., (2009) who reported the presence of terpenes in F. mucoso. However, the observation that terpene-rich dichloromethane fraction (TRDF) had a higher content of terpenes when compared with terpene-rich ethylacetate fraction (TREF) is in order since terpenes are non-polar, they are therefore expected to be present in greater amount in a non-polar solvent (dichloromethane) relative to a more polar solvent (ethylacetate).

Plant terpenes have been shown to exhibit potential anti-inflammatory and antioxidant activity (GonzálezBurgos et al., 2012; Vega et al., 2018; Li et al., 2019). In this study, the observation that TRDF and TREF ameliorated LPS-induced production of inflammatory cytokines and restored antioxidant enzyme activity may be attributed to the anti-inflammatory and antioxidant activities of the terpenes present in the fractions. Furthermore, the observation that the terpene-rich fractions alone maintained basal levels of pro-inflammatory cytokines while preserving antioxidant activity is a pointer to the anti-inflammatory and antioxidant potential of the plant (Bouquet, 1969; Essien et al., 2016, Oguntoye et al., 2016). In addition, the finding that TRDF is more potent that TREF in reducing levels of pro-inflammatory cytokines may be due to higher content of terpenes present in TRDF than TREF. 
The levels of serum/plasma AST and ALT usually serves as specific indicators of liver injury clinically (Senior, 2012). The results obtained in this study agree with those of Chen et al. (2019), who reported that LPS induced inflammatory cell infiltration and caused significant increases in levels of AST and ALT, as well as accompanying hepatocyte necrosis. The findings that a combination of LPS with TRDF significantly reduced LPS-induced elevation of AST and ALT is a pointer to the hepato-protective potential of this fraction (TRDF). In addition, the histological analysis confirmed/underscored the hepatic pathological change in livers of LPS- induced mice (Jiang et al., 2018) as well as the dose-dependent protective effect of TRDF with or without LPS challenge, while the histological evaluation of control livers showed the expected normal architecture with no pathological signs.

In this study, the administration of TREF alone brought about a significant elevation in the levels of the liver marker enzymes relative to control while a mild reduction in enzyme activities was observed when the low dose $(100 \mathrm{mg} / \mathrm{kg})$ of TREF was co-administered with LPS while the high dose $(200 \mathrm{mg} / \mathrm{kg}) \mathrm{had}$ no effect on liver AST and ALT. These are indications that although TREF possesses antioxidant and antiinflammatory activities, these pharmacological potentials could not protect the liver from injury as further emphasized by histological examination. This prompted further investigation into the mechanism of protective effects offered largely by TRDF, but not TREF.

Mitochondrial swelling (matrix expansion) is an important parameter to assess inner membrane permeability transition and this provides information, in part, as to the health of the organelle. The mPT pore is a potential drug target for the treatment of a myriad of diseases (Kalani et al., 2018; Bhosale, et al., 2019). In this regard, inducers of pore opening trigger cell death in diseases characterized by cell death insufficiency while MPT pore inhibitors are useful in preventing pathological changes associated with excessive cell death. As observed earlier in the preliminary study, LPS significantly stimulated liver mitochondrial swelling indicating that the status of the mitochondria could be manipulated by bacteria during infection. The observation that mitochondria isolated from mice treated with TRDF (without LPS) has intact inner mitochondrial membrane while those isolated from mice that received a combination of LPS and TRDF significantly inhibited LPS-induced pore opening is an attestation to the protective effect of TRDF. It is also noteworthy that doses of TRDF inhibited mitochondrial swelling better than spermine, a standard mPT blocker. Furthermore, the inductive effect of TREF alone on MPT pore may account for the pathological effects seen in the histological sections of the liver as well as observed elevated liverspecific enzymes. Interestingly, the finding that TREF inhibited opening of the MPT pore at the low dose $(100 \mathrm{mg} / \mathrm{kg})$, but had a higher magnitude of mitochondrial swelling (5.2 folds) at high dose $(200 \mathrm{mg} / \mathrm{kg})$ greater than LPS alone (3.3 folds) suggests that TREF may have beneficial or protective effects only at low doses.

The finding that TRDF and TREF inhibited LPS-induced increase in mitochondrial lipid peroxidation at all the doses used in this study to varying extents confirm that the modulation of pore opening effects exerted by these fractions were not due to any disruption of the mitochondrial membrane bilayer. These 
data are in consonance with the studies of Singh et al., (2012) that revealed that natural terpenes prevented oxidative mitochondrial dysfunction during toxicant-induced hepatic damage.

Although, it is well established that disruption or opening of the MPT pore results in bioenergetics collapse or decrease in ATP levels which is usually seen in enhancement of mATPase activity, it is still a matter of debate as to whether the ATP synthase is a strong candidate of the pore (Bernadi et al., 2018). An assessment of mATPase in mice that received TRDF with LPS revealed that TRDF significantly inhibited LPS-enhanced mATPase activity. This suggests that TRDF preserved the bioenergetics status of the mitochondria while TREF with (except at the low dose) / without LPS compromised the energy status of the organelle as shown by high levels of inorganic phosphate released relative to the control.

In our attempt to further understand the underlying bioactive metabolites that are possibly responsible for the observed pharmacological activities in this study, terpene-rich solvent fractions of $F$. mucoso was analyzed with UPLC hyphenated with a high definition ESI-MS. The identified constituents of both TRDF and TREF revealed some similarities in the compound classes as observed with the fatty acid derivatives, esters, lactone bearing compounds and isoprenylated flavonoids. However, variation in the pharmacophoric combinations across the compounds which impose either positive or negative synergy is likely responsible for the bioactivity differences between TRDF and TREF. The functional groups that constitute each pharmacophore interact with the target receptors in varying degrees, positively or negatively (Efferth and Koch, 2011).

The monoterpene lactone, loliolide which was identified in both TRDF and TREF was recently described as a potent anti-inflammatory and neuroprotective metabolite (Silva et al., 2021). Similarly, aesculetin and several other coumarins derivatives are well known anti-inflammatory agents (Grover \& Jachak, 2015). A common pharmacophore that may be responsible for activities observed in loliolide and aesculetin is the a, $\beta$-unsaturated lactone moiety. Osajin had initially displayed significant anti-inflammatory activity (Abourashed et al., 2015) like other isoflavones such as daidzein and genistein (Yu et al., 2016). Some 3isoprenylated flavones have been reported to possess significant anti-inflammatory (Wei et al., 2005), antioxidant (Lin et al., 2009) and hepatoprotective (An et al., 2006) activities. Nigrasin $\mathrm{H}$ and I which were originally isolated alongside the epimeric sanggenon-type flavanone, nigrasin A from a different Moraceae plant, Morus nigra (Hu et al., 2011) belong to this class.

A terpene-dominated ${ }^{1} \mathrm{H}$ NMR fingerprint was obtained for TRDF as evident in the highly overlapping upfield chemical shifts with strong intensities. The strong singlets between $\delta_{H} 0.79$ and 1.29 are characteristic of angular methyl protons of the terpenoids. The olefinic proton(s) triterpenes and some other terpenoids often find resonances between $\delta_{H} 5.13$ and 5.36 (for example, $\delta_{H} 5.21$ in ursolic acid), although terminal methylene protons resonate around $\delta_{H} 4.50$ to 4.69 . Oxygenated methylene and methine signals which are major components of $(3 \beta, 5 a, 6 \beta)$-androstane-3,5,6-triol, ursolic acid, glycol stearate, the glycolipid and other terpenoids present in TRDF must have given rise to the signals observed around $\delta_{H} 3.23$ and 4.58 which may be further deshielded to about $\delta_{H} 5.42$ for some anomeric protons. Presence of few aromatic metabolites was registered in TRDF which were revealed by low intensity peaks 
between $\delta_{H} 6.11$ and 7.72. Amongst the identified aromatic compounds are aesculetin, galvaquinone $A$ and osajin. The ${ }^{1} \mathrm{H}$ NMR fingerprint therefore provides qualitative credence to the identity of the metabolites identified in TRDF.

\section{Conclusion}

Put together, we have shown for the first time the anti-inflammatory potential of Ficus mucoso. The TRDF is more potent than TREF with respect to beneficial hepatoprotective effects against LPS-induced inflammation.Thus, augmenting the antioxidant defense system and inhibition of mPT opening is important especially during infections or periods of chronic oxidative insult. Therefore, isolation and characterization of terpenes in $F$. mucoso as well as their molecular targets is highly desirable in finding novel specific anti-inflammatory drugs.

\section{Declarations}

\section{Funding}

This research received no external funding

\section{Conflicts of interest/Competing interests}

The authors declare that they have no known competing financial interests or personal relationships that could have appeared to influence the work reported in this paper.

Availability of data and material (Available on request)

Code availability (NA)

Authors' contributions

Conceptualization: OT Oyebode and JO Olanlokun. Data curation, Formal analysis, Investigation, Methodology, Project administration: O. Salami, I. Obi, OT Oyebode, O. Bodede, JO Olanlokun, Writing original draft: ОT Oyebode, O. Bodede, JO Olanlokun, Validation, Supervision, Review and Editing: G. Prinsloo, 00. Olorunsogo

\section{Ethics approval}

The ethical approval for this study was obtained from the University of Ibadan Animal Care \& Use Research Ethics Committee (UI-ACUREC/2019/0167) which conformed to that of NIH and was strictly adhered to.

Consent to participate (NA)

Consent for publication (NA) 


\section{References}

1. Abourashed EA, Abraha A, Khan SI, et al (2015) Potential of Horse Apple Isoflavones in Targeting Inflammation and Tau Protein Fibrillization. Natural product communications 10:1577-1580

2. Adám-Vizi V, Seregi A (1982) Receptor independent stimulatory effect of noradrenaline on $\mathrm{Na}, \mathrm{K}$ ATPase in rat brain homogenate. Role of lipid peroxidation. Biochemical pharmacology 31:22312236. https://doi.org/10.1016/0006-2952(82)90106-x

3. Aebi H (1984) [13] Catalase in Vitro. Methods in Enzymology 105:121-126. https://doi.org/10.1016/S0076-6879(84)05016-3

4. An R-B, Sohn D-H, Kim Y-C (2006) Hepatoprotective compounds of the roots of Cudrania tricuspidata on tacrine-induced cytotoxicity in Hep G2 cells. Biological \& pharmaceutical bulletin 29:838-840. https://doi.org/10.1248/bpb.29.838

5. Bassir O (1963) Handbook of practical biochemistry. Ibadan University press, Ibadan, Nigeria. p13.

6. Battaglia V, Salvi M, Toninello A (2005) Oxidative stress is responsible for mitochondrial permeability transition induction by salicylate in liver mitochondria. The Journal of biological chemistry 280:33864-33872. https://doi.org/10.1074/jbc.M502391200

7. Bauer TM, Murphy E (2020) Role of Mitochondrial Calcium and the Permeability Transition Pore in Regulating Cell Death. Circulation research 126:280-293.

https://doi.org/10.1161/CIRCRESAHA.119.316306

8. Bernardi P (2018) Why F-ATP Synthase Remains a Strong Candidate as the Mitochondrial Permeability Transition Pore. Frontiers in physiology 9:1543.

https://doi.org/10.3389/fphys.2018.01543

9. Bhosale G, Duchen MR (2019) Investigating the Mitochondrial Permeability Transition Pore in Disease Phenotypes and Drug Screening. Current protocols in pharmacology 85:e59. https://doi.org/10.1002/cpph.59

10. Bouquet, A (1969) Féticheurs et médecine traditionnelles du Congo (Brazzaville). Mémoires O.R.S.T.O.M., No. 36,282 p.

11. Brealey D, Brand M, Hargreaves I, et al (2002) Association between mitochondrial dysfunction and severity and outcome of septic shock. Lancet (London, England) 360:219-223. https://doi.org/10.1016/S0140-6736(02)09459-X

12. Chen $L$, Deng $H$, Cui $H$, et al (2018) Inflammatory responses and inflammation-associated diseases in organs. Oncotarget 9:7204-7218. https://doi.org/10.18632/oncotarget.23208

13. Chen Z, Yang Y, Mi S, et al (2019) Hepatoprotective effect of chlorogenic acid against chronic liver injury in inflammatory rats. Journal of Functional Foods 62:103540.

https://doi.org/10.1016/j.jff.2019.103540

14. Corner EJH, Corner EJH (1962) The Classification of Moraceae. The Gardens' bulletin, Singapore 19:187-252 
15. Crompton M (1999) The mitochondrial permeability transition pore and its role in cell death. The Biochemical journal 341 ( Pt 2:233-249

16. Crouser ED, Julian MW, Huff JE, et al (2004) Abnormal permeability of inner and outer mitochondrial membranes contributes independently to mitochondrial dysfunction in the liver during acute endotoxemia. Critical care medicine 32:478-488. https://doi.org/10.1097/01.CCM.0000109449.99160.81

17. Djemgou PC, Ngandeu F, Hegazy ME, et al (2009) GC-MS analysis of terpenes from ficus mucuso. Pharmacogn Res 1:197-201

18. Efferth T, Koch E (2011) Complex interactions between phytochemicals. The multi-target therapeutic concept of phytotherapy. Current drug targets 12:122-132.

https://doi.org/10.2174/138945011793591626

19. Essien E, Newby J, Walker T, et al (2016) Essential oil constituents, anticancer and antimicrobial activity of Ficus mucoso and Casuarina equisetifolia leaves. American Journal of Essential Oils and Natural Products 4:1-6

20. Ferguson,NM (1956) "A textbook of pharmacognosy," California Medicine, vol. 72, no. 1, p. 77.

21. Furman D, Campisi J, Verdin E, et al (2019) Chronic inflammation in the etiology of disease across the life span. Nature medicine 25:1822-1832. https://doi.org/10.1038/s41591-019-0675-0

22. Glass CK, Saijo K, Winner B, et al (2010) Mechanisms underlying inflammation in neurodegeneration. Cell 140:918-934. https://doi.org/10.1016/j.cell.2010.02.016

23. González-Burgos E, Gómez-Serranillos MP (2012) Terpene compounds in nature: a review of their potential antioxidant activity. Current medicinal chemistry 19:5319-5341. https://doi.org/10.2174/092986712803833335

24. Grover J, Jachak SM (2015) Coumarins as privileged scaffold for anti-inflammatory drug development. RSC Advances 5:38892-38905. https://doi.org/10.1039/C5RA05643H

25. Halestrap AP, Clarke SJ, Javadov SA (2004) Mitochondrial permeability transition pore opening during myocardial reperfusion-a target for cardioprotection. Cardiovascular research 61:372-385. https://doi.org/10.1016/S0008-6363(03)00533-9

26. Halestrap AP, Richardson AP (2015) The mitochondrial permeability transition: a current perspective on its identity and role in ischaemia/reperfusion injury. Journal of molecular and cellular cardiology 78:129-141. https://doi.org/10.1016/j.yjmcc.2014.08.018

27. Hamesch K, Borkham-Kamphorst E, Strnad P, Weiskirchen R (2015) Lipopolysaccharide-induced inflammatory liver injury in mice. Laboratory animals 49:37-46. https://doi.org/10.1177/0023677215570087

28. Hu X, Wu J-W, Zhang X-D, et al (2011) Isoprenylated flavonoids and adipogenesis-promoting constituents from Morus nigra. Journal of natural products 74:816-824. https://doi.org/10.1021/np100907d

29. Jiang Z, Meng Y, Bo L, et al (2018) Sophocarpine Attenuates LPS-Induced Liver Injury and Improves Survival of Mice through Suppressing Oxidative Stress, Inflammation, and Apoptosis. Mediators of 
Inflammation 2018:1-12. https://doi.org/10.1155/2018/5871431

30. Johnson D, Lardy H (1967) [15] Isolation of liver or kidney mitochondria. Methods in Enzymology 10:94-96. https://doi.org/10.1016/0076-6879(67)10018-9

31. Kalani K, Yan SF, Yan SS (2018) Mitochondrial permeability transition pore: a potential drug target for neurodegeneration. Drug discovery today 23:1983-1989.

https://doi.org/10.1016/j.drudis.2018.08.001

32. Lapidus RG, Sokolove PM (1994) The mitochondrial permeability transition. Interactions of spermine, ADP, and inorganic phosphate. The Journal of biological chemistry 269:18931-18936

33. Li F, Zhang J, Lin M, et al (2019) Anti-inflammatory terpenes from Schefflera rubriflora C. J. Tseng \& G. Hoo with their TNF-a and IL-6 inhibitory activities. Phytochemistry 163:23-32. https://doi.org/10.1016/j.phytochem.2019.03.021

34. Lin KW, Liu CH, Tu HY, et al (2009) Antioxidant prenylflavonoids from Artocarpus communis and Artocarpus elasticus. Food Chemistry 115:558-562.

https://doi.org/10.1016/J.FOODCHEM.2008.12.059

35. Liu Y, Li F, Zhang L, et al (2017) Taurine alleviates lipopolysaccharide-induced liver injury by anti-inflammation and antioxidants in rats. Molecular medicine reports 16:6512-6517. https://doi.org/10.3892/mmr.2017.7414

36. LOWRY OH, ROSEBROUGH NJ, FARR AL, RANDALL RJ (1951) Protein measurement with the Folin phenol reagent. The Journal of biological chemistry 193:265-275. https://doi.org/10.1016/0922338X(96)89160-4

37. Magnani L, Gaydou E, Hubaud J (2000) Spectrophotometric measurement of antioxidant properties of flavones and flavonols against superoxide anion. Analytica Chimica Acta 411:209-216. https://doi.org/10.1016/S0003-2670(00)00717-0

38. Medzhitov R (2008) Origin and physiological roles of inflammation. Nature 454:428-435. https://doi.org/10.1038/nature07201

39. Misra HP, Fridovich I (1972) The role of superoxide anion in the autoxidation of epinephrine and a simple assay for superoxide dismutase. The Journal of biological chemistry 247:3170-3175

40. Missiroli S, Genovese I, Perrone M, et al (2020) The Role of Mitochondria in Inflammation: From Cancer to Neurodegenerative Disorders. Journal of clinical medicine 9:. https://doi.org/10.3390/jcm9030740

41. Mohanty A, Tiwari-Pandey R, Pandey NR (2019) Mitochondria: the indispensable players in innate immunity and guardians of the inflammatory response. Journal of cell communication and signaling 13:303-318. https://doi.org/10.1007/s12079-019-00507-9

42. Najafı M, Farajnia S, Mohammadi M, et al (2014) Inhibition of mitochondrial permeability transition pore restores the cardioprotection by postconditioning in diabetic hearts. Journal of diabetes and metabolic disorders 13:106. https://doi.org/10.1186/s40200-014-0106-1

43. Oguntoyea SO, Hamid AA, Ajibade SO, et al (2016) GC-MS analysis, antioxidant and antimicrobial activities of extracts from Ficus mucoso leaves. Nigerian Journal of Chemical Research 21:51-65. 
https://doi.org/10.4314/njcr.v21i1.

44. Olorunsogo 00, Bababunmi EA, Bassir O (1979) Effect of glyphosate on rat liver mitochondria in vivo. Bulletin of environmental contamination and toxicology 22:357-364. https://doi.org/10.1007/BF02026955

45. Olorunsogo 0O, Malomo SO (1985) Sensitivity of oligomycin-inhibited respiration of isolated rat liver mitochondria to perfluidone, a fluorinated arylalkylsulfonamide. Toxicology 35:231-240. https://doi.org/10.1016/0300-483X(85)90018-6

46. Olowofolahan A, Oludele O, Olorunsogo O (2020) GCMS analysis of partially purified chloroform sub fractions of methanol extract of drymaria cordata (Linn) and their effects on mitochondrial membrane permeability transition pore. 8:3-11

47. Oludele O, Idris B, Benard O, et al (2018) Mondia whitei, an African Spice Inhibits Mitochondrial Permeability Transition in Rat Liver. Preventive nutrition and food science 23:206-213. https://doi.org/10.3746/pnf.2018.23.3.206

48. Oyebode OT, Abolaji AO, Oluwadare JO, et al (2020) Apigenin ameliorates D-galactose-induced lifespan shortening effects via antioxidative activity and inhibition of mitochondrial-dependent apoptosis in Drosophila melanogaster. Journal of Functional Foods 69:. https://doi.org/10.1016/J.JFF.2020.103957

49. Oyebode OT, Ogunbiyi FO, Olorunsogo 00 (2019) Opening of liver mitochondrial permeability transition pore in streptozotocin-induced diabetic rats and its inhibition by methanol fraction of Ficus mucoso (Welw) root bark. Journal of Integrative Medicine 17:446-454. https://doi.org/10.1016/j.joim.2019.10.001

50. Oyebode TO, Adebusuyi OT, Akintimehin SE, Olorunsogo OO (2017) Modulation of Cytochrome C Release and Opening of Mitochondrial Permeability Transition Pore by Calliandra portoricensis (Benth) Root Bark Methanol Extract. European Journal of Medicinal Plants 20:1-14. https://doi.org/10.9734/EJMP/2017/35211

51. Pereira-Leite C, Nunes C, Jamal SK, et al (2017) Nonsteroidal Anti-Inflammatory Therapy: A Journey Toward Safety. Medicinal research reviews 37:802-859. https://doi.org/10.1002/med.21424

52. Pourahmad J, Mortada Y, Eskandari MR, Shahraki J (2011) Involvement of Lysosomal Labilisation and Lysosomal/mitochondrial Cross-Talk in Diclofenac Induced Hepatotoxicity. Iranian journal of pharmaceutical research: IJPR 10:877-887

53. Prakash V (2017) Terpenoids as source of anti-inflammatory compounds. Asian Journal of Pharmaceutical and Clinical Research 10:68-76. https://doi.org/10.22159/ajpcr.2017.v10i3.16435

54. Rahman AHMM, Khanom A (2013) A Taxonomic and Ethno-Medicinal Study of Species from Moraceae (Mulberry) Family in Bangladesh Flora. Research in Plant Sciences 1:53-57. https://doi.org/10.12691/PLANT-1-3-1

55. REITMAN S, FRANKEL S (1957) A colorimetric method for the determination of serum glutamic oxalacetic and glutamic pyruvic transaminases. American journal of clinical pathology 28:56-63. https://doi.org/10.1093/ajcp/28.1.56 
56. Rimessi A, Previati M, Nigro F, et al (2016) Mitochondrial reactive oxygen species and inflammation: Molecular mechanisms, diseases and promising therapies. The international journal of biochemistry \& cell biology 81:281-293. https://doi.org/10.1016/j.biocel.2016.06.015

57. Salimi A, Neshat MR, Naserzadeh P, Pourahmad J (2019) Mitochondrial Permeability Transition Pore Sealing Agents and Antioxidants Protect Oxidative Stress and Mitochondrial Dysfunction Induced by Naproxen, Diclofenac and Celecoxib. Drug research 69:598-605. https://doi.org/10.1055/a-08669356

58. Senior JR (2012) Alanine aminotransferase: a clinical and regulatory tool for detecting liver injurypast, present, and future. Clinical pharmacology and therapeutics 92:332-339. https://doi.org/10.1038/clpt.2012.108

59. Silva J, Alves C, Martins A, et al (2021) Loliolide, a New Therapeutic Option for Neurological Diseases? In Vitro Neuroprotective and Anti-Inflammatory Activities of a Monoterpenoid Lactone Isolated from Codium tomentosum. International journal of molecular sciences 22: https://doi.org/10.3390/ijms22041888

60. Singh BK, Tripathi M, Chaudhari BP, et al (2012) Natural terpenes prevent mitochondrial dysfunction, oxidative stress and release of apoptotic proteins during nimesulide-hepatotoxicity in rats. PloS one 7:e34200. https://doi.org/10.1371/journal.pone.0034200

61. Supinski GS, Schroder EA, Callahan LA (2020) Mitochondria and Critical Illness. Chest 157:310-322. https://doi.org/10.1016/j.chest.2019.08.2182

62. Varshney R, Kale RK (1990) Effects of calmodulin antagonists on radiation-induced lipid peroxidation in microsomes. International Journal of Radiation Biology 58:733-743. https://doi.org/10.1080/09553009014552121

63. Vega RJS, Xolalpa NC, Castro AJA, et al (2018) Terpenes from Natural Products with Potential AntiInflammatory Activity. Terpenes and Terpenoids. https://doi.org/10.5772/INTECHOPEN.73215

64. Wei B-L, Weng J-R, Chiu P-H, et al (2005) Antiinflammatory flavonoids from Artocarpus heterophyllus and Artocarpus communis. Journal of agricultural and food chemistry 53:3867-3871. https://doi.org/10.1021/jf047873n

65. Yu J, Bi X, Yu B, Chen D (2016) Isoflavones: Anti-Inflammatory Benefit and Possible Caveats. Nutrients 8:. https://doi.org/10.3390/nu8060361

\section{Tables}

Table 1. UPLC-ESI-MS report of terpene-rich dichloromethane fraction (TRDF) 


\begin{tabular}{|c|c|c|c|c|c|c|}
\hline$S / N$ & $t_{R}(\min )$ & $\begin{array}{l}\text { Compound } \\
\text { identified }\end{array}$ & Formula & DBE & Found mass $(\mathrm{m} / \mathrm{z})$ & Adduct \\
\hline 1 & 5.68 & Esculetin & $\mathrm{C}_{9} \mathrm{H}_{5} \mathrm{O}_{4}$ & 7 & 177.0189 & {$[\mathrm{M}-\mathrm{H}]^{-}$} \\
\hline 2 & 5.80 & Loliolide & $\mathrm{C}_{11} \mathrm{H}_{17} \mathrm{O}_{3}$ & 4 & 197.1177 & {$[\mathrm{M}+\mathrm{H}]^{+}$} \\
\hline 3 & 6.13 & Azelaic acid & $\mathrm{C}_{9} \mathrm{H}_{15} \mathrm{O}_{4}$ & 2 & 187.0970 & {$[\mathrm{M}-\mathrm{H}]^{-}$} \\
\hline 4 & 9.24 & Nonanamide & $\mathrm{C}_{9} \mathrm{H}_{20} \mathrm{NO}$ & 1 & 158.1529 & {$[\mathrm{M}+\mathrm{H}]^{+}$} \\
\hline 5 & 9.33 & Nopalinic acid & $\mathrm{C}_{10} \mathrm{H}_{19} \mathrm{~N}_{2} \mathrm{O}_{6}$ & 3 & 263.1255 & {$[\mathrm{M}+\mathrm{H}]^{+}$} \\
\hline 6 & 12.64 & Galvaquinone A & $\mathrm{C}_{21} \mathrm{H}_{21} \mathrm{O}_{5}$ & 12 & 353.1376 & {$[\mathrm{M}+\mathrm{H}]^{+}$} \\
\hline 7 & 13.26 & $\begin{array}{l}\text { Octadecanedioic } \\
\text { acid }\end{array}$ & $\mathrm{C}_{18} \mathrm{H}_{33} \mathrm{O}_{4}$ & 2 & 313.2406 & {$[\mathrm{M}-\mathrm{H}]^{-}$} \\
\hline 8 & 14.26 & Osajin & $\mathrm{C}_{25} \mathrm{H}_{23} \mathrm{O}_{5}$ & 14 & 403.1536 & {$[\mathrm{M}-\mathrm{H}]^{-}$} \\
\hline 9 & 14.67 & $\begin{array}{l}(3 \beta, 5 \alpha, 6 \beta)- \\
\text { Androstane-3,5,6- } \\
\text { triol }\end{array}$ & $\mathrm{C}_{19} \mathrm{H}_{33} \mathrm{O}_{3}$ & 4 & 309.2444 & {$[\mathrm{M}+\mathrm{H}]^{+}$} \\
\hline 10 & 14.93 & Ursolic acid & $\mathrm{C}_{30} \mathrm{H}_{47} \mathrm{O}_{3}$ & 7 & 455.3515 & {$[\mathrm{M}-\mathrm{H}]^{-}$} \\
\hline 11 & 15.92 & Glycol stearate & $\mathrm{C}_{20} \mathrm{H}_{39} \mathrm{O}_{3}$ & 1 & 327.2919 & {$[\mathrm{M}-\mathrm{H}]^{-}$} \\
\hline 12 & 17.64 & $\begin{array}{l}\alpha \text {-D- } \\
\text { Glucopyranoside, } \beta \text { - } \\
\text { D-fructofuranosyl, } \\
\text { 6-tricosanoate }\end{array}$ & $\mathrm{C}_{35} \mathrm{H}_{67} \mathrm{O}_{12}$ & 3 & 679.4569 & {$[\mathrm{M}+\mathrm{H}]^{+}$} \\
\hline
\end{tabular}

Table 2. UPLC-ESI-MS report of terpene-rich ethyl acetate fraction (TREF)

\begin{tabular}{|c|c|c|c|c|c|c|}
\hline $\begin{array}{l}\mathrm{S} / \\
\mathrm{N} \\
\end{array}$ & $t_{R}(\min )$ & Compound identified & Formula & DBE & $\begin{array}{l}\text { Found mass } \\
\qquad(\mathrm{m} / \mathrm{z})\end{array}$ & Adducts \\
\hline 1 & 4.99 & Vanillic acid & $\mathrm{C}_{8} \mathrm{H}_{7} \mathrm{O}_{4}$ & 5 & 167.0337 & {$[\mathrm{M}-\mathrm{H}]^{-}$} \\
\hline 2 & 5.82 & Loliolide & $\mathrm{C}_{11} \mathrm{H}_{17} \mathrm{O}_{3}$ & 4 & 197.1182 & {$[\mathrm{M}+\mathrm{H}]^{+}$} \\
\hline 3 & 6.13 & Azelaic acid & $\mathrm{C}_{9} \mathrm{H}_{15} \mathrm{O}_{4}$ & 2 & 187.0950 & {$[\mathrm{M}-\mathrm{H}]^{-}$} \\
\hline 4 & 7.06 & Sebacic acid & $\mathrm{C}_{10} \mathrm{H}_{17} \mathrm{O}_{4}$ & 2 & 201.1105 & {$[\mathrm{M}-\mathrm{H}]^{-}$} \\
\hline 5 & 7.69 & Tributyrin & $\mathrm{C}_{15} \mathrm{H}_{25} \mathrm{O}_{6}$ & 3 & 301.1685 & {$[\mathrm{M}-\mathrm{H}]^{-}$} \\
\hline 6 & 8.44 & Pinellic acid & $\mathrm{C}_{18} \mathrm{H}_{33} \mathrm{O}_{5}$ & 2 & 329.2297 & {$[\mathrm{M}-\mathrm{H}]^{-}$} \\
\hline 7 & 8.88 & Phoenixoside B & $\mathrm{C}_{18} \mathrm{H}_{29} \mathrm{O}_{12}$ & 4 & 437.1558 & {$[\mathrm{M}-\mathrm{H}]^{-}$} \\
\hline 8 & 9.22 & Nigrasin A & $\mathrm{C}_{25} \mathrm{H}_{25} \mathrm{O}_{8}$ & 13 & 453.1552 & {$[\mathrm{M}-\mathrm{H}]^{-}$} \\
\hline 9 & 10.16 & Nigrasin $\mathrm{H}$ & $\mathrm{C}_{25} \mathrm{H}_{25} \mathrm{O}_{6}$ & 13 & 421.1696 & {$[\mathrm{M}-\mathrm{H}]^{-}$} \\
\hline 10 & 10.31 & Nigrasin I & $\mathrm{C}_{25} \mathrm{H}_{25} \mathrm{O}_{6}$ & 13 & 421.1682 & {$[\mathrm{M}-\mathrm{H}]^{-}$} \\
\hline 11 & 12.83 & labdan-8 $\alpha$-ol-15-yl-(3-methylpentanoate) & $\mathrm{C}_{26} \mathrm{H}_{49} \mathrm{O}_{3}$ & 3 & 409.3762 & {$[\mathrm{M}+\mathrm{H}]^{+}$} \\
\hline 12 & 15.92 & Rutamarin & $\mathrm{C}_{21} \mathrm{H}_{23} \mathrm{O}_{5}$ & 10 & 355.1567 & {$[\mathrm{M}-\mathrm{H}]^{-}$} \\
\hline
\end{tabular}

\section{Figures}



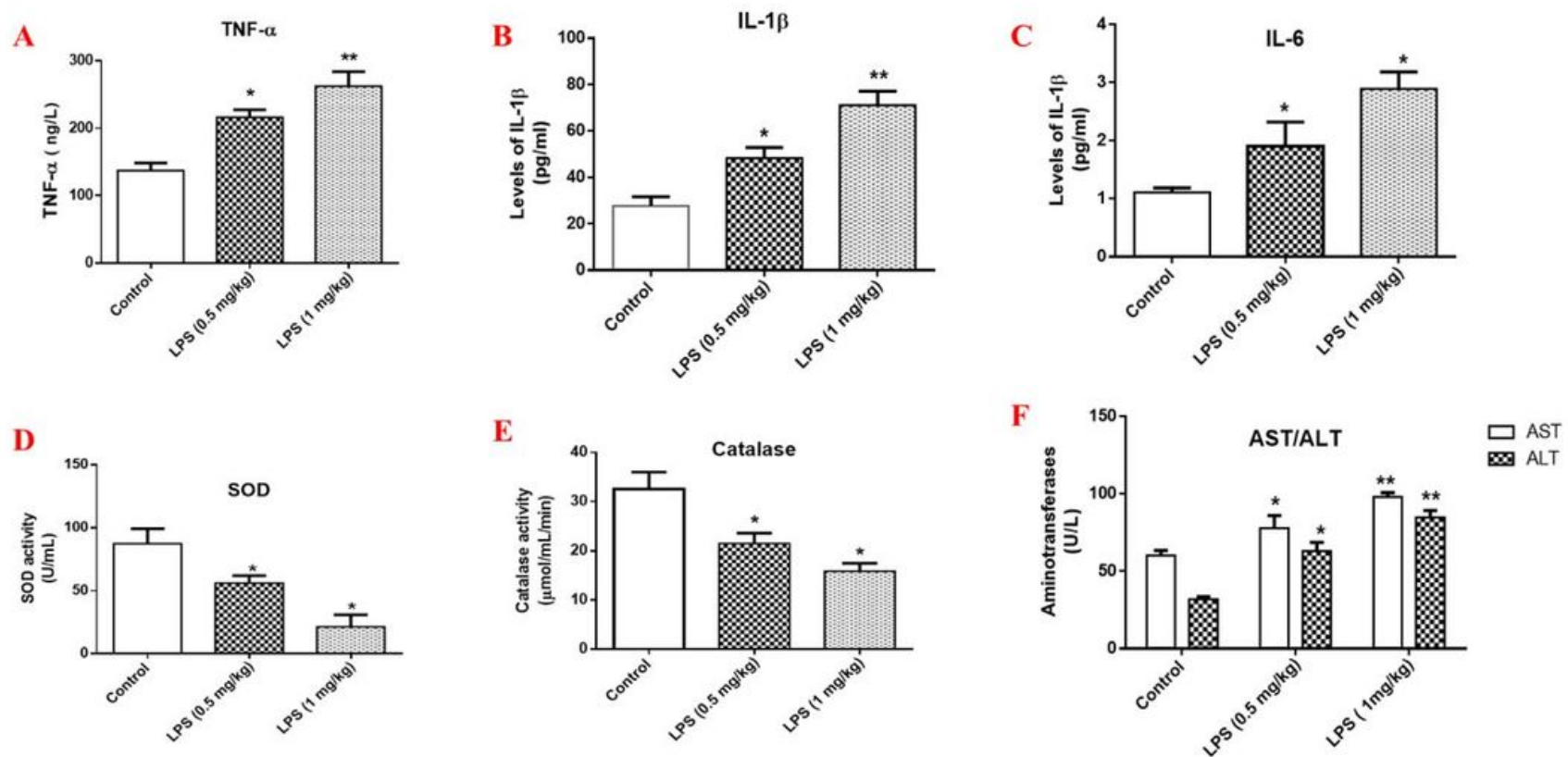

\section{Figure 1}

Effects of administration of doses of lipopolysaccharide (LPS) on liver antioxidant parameters, aminotransferases and pro-inflammatory cytokines in mice. Charts are represented as: Tumour-necrosis factor (TNF-a) (A), Levels of IL-1 $\beta$ (B), Levels of IL-6 (C) Superoxide dismutase activity (D), Catalase activity $(E)$, levels of aminotransferases $(F)$. Values are expressed as Mean \pm Standard Error of Mean with 3 replicates per treatment group. Significant differences from the control are indicated by $*(p<0.05), \star \star(p$ $<0.01)$ 


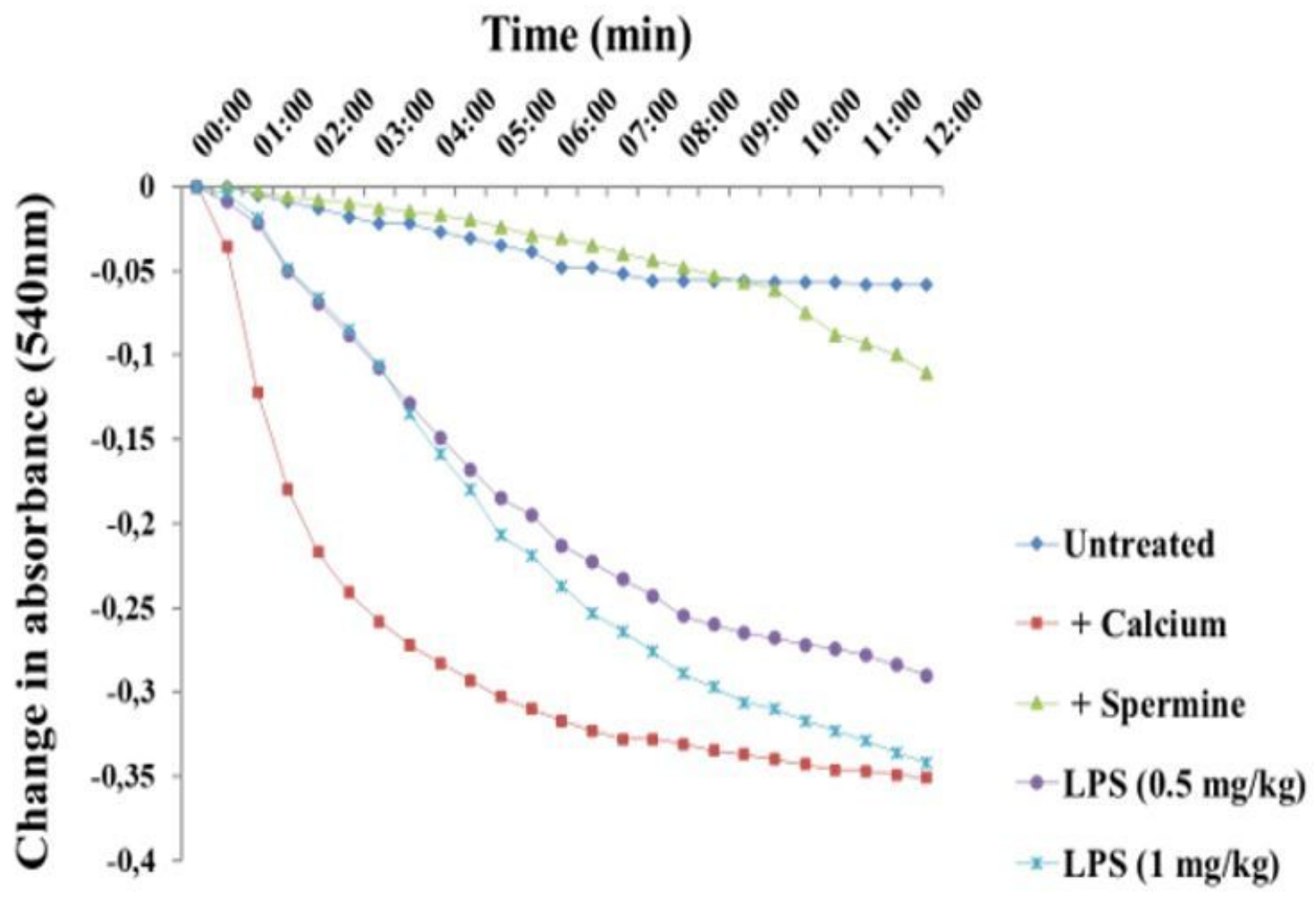

Figure 2

Representative profile of changes in absorbance of mitochondria isolated from livers of rats previously exposed (intraperitoneally) to doses of lipopolysaccharide (LPS) for a period of $72 \mathrm{hrs.}{ }^{*}$ Typical data of one experiment are shown and similar results were obtained in at least three different preparations 


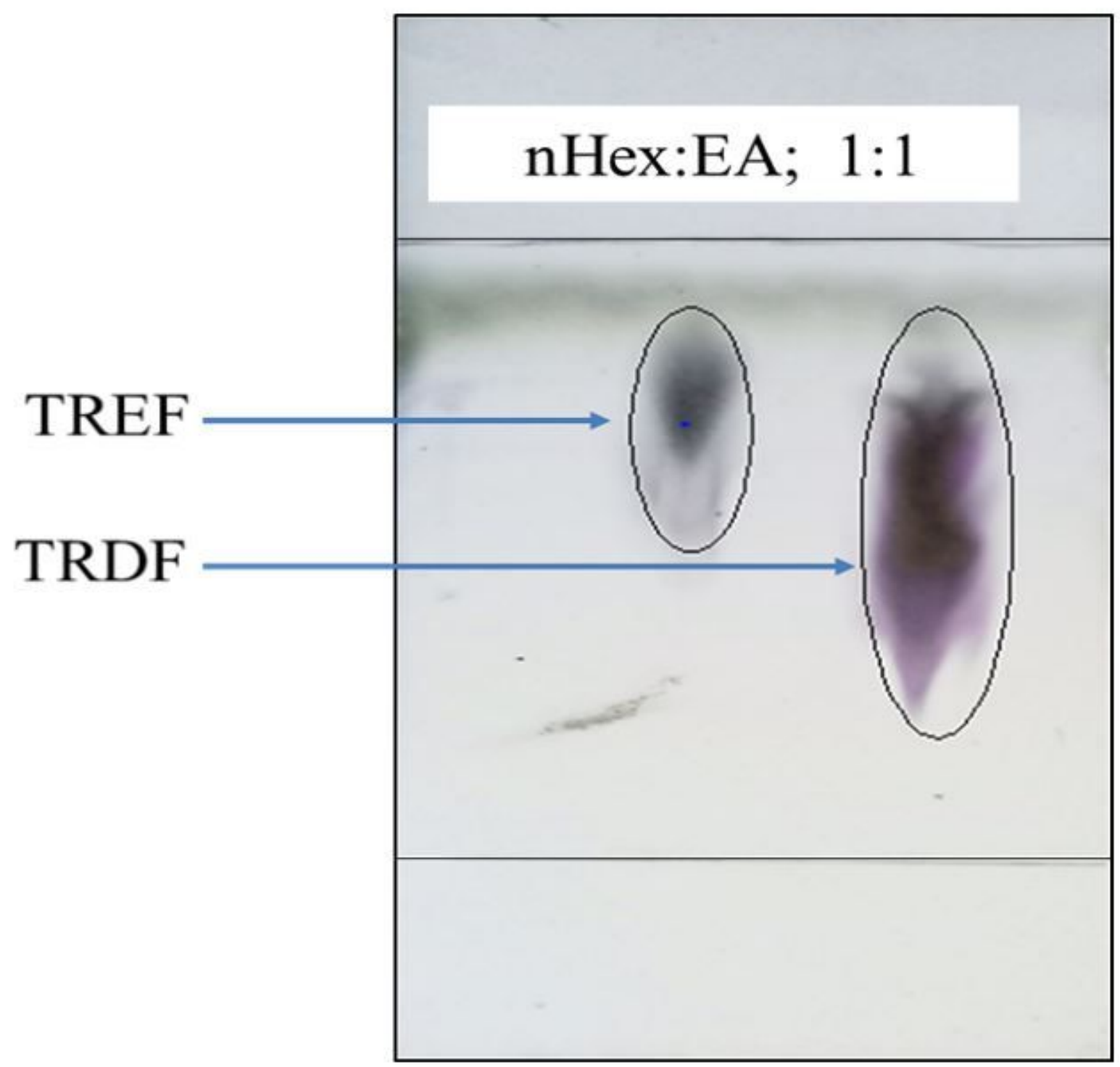

Figure 3

Terpenes detected in Terpene-Rich fractions of Ficus mucoso. Solvent system: n-Hexane/Ethylacetate 1:1 TRDF - Terpene-Rich Dichloromethane fraction of Ficus mucoso. TREF- Terpene-Rich Ethylacetate fraction of Ficus mucoso 


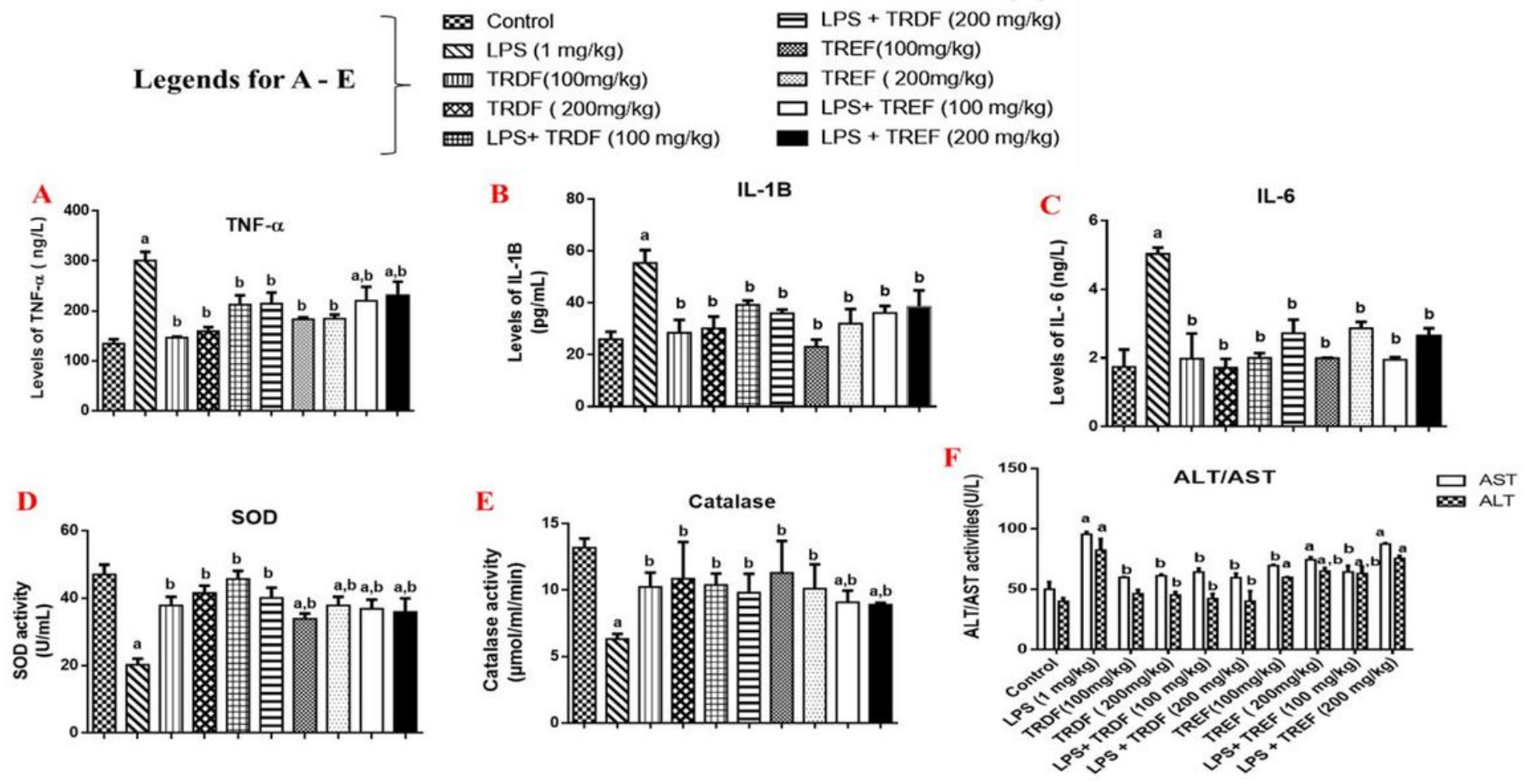

Figure 4

Effects of administration of terpene-rich fractions of F. mucoso on liver antioxidant parameters, aminotransferases and pro-inflammatory cytokines in Lipopolysaccharide-treated mice. Charts are represented as: Tumour-necrosis factor TNF-a (A), Levels of IL-1 $\beta(B)$, Levels of IL-6 (C), Superoxide dismutase activity (D), Catalase activity (E), levels of aminotransferases (F).TRDF- Terpene-Rich Dichloromethane Fraction of F. mucoso. TREF- Terpene-Rich Ethylacetate Fraction of F. mucoso. Values are expressed as Mean \pm Standard Error of Mean with 3 replicates per treatment group. Significant differences from the control are indicated by a $(p<0.05)$. Significant differences from the LPS-treated group indicated by $b(p<0.05)$. 

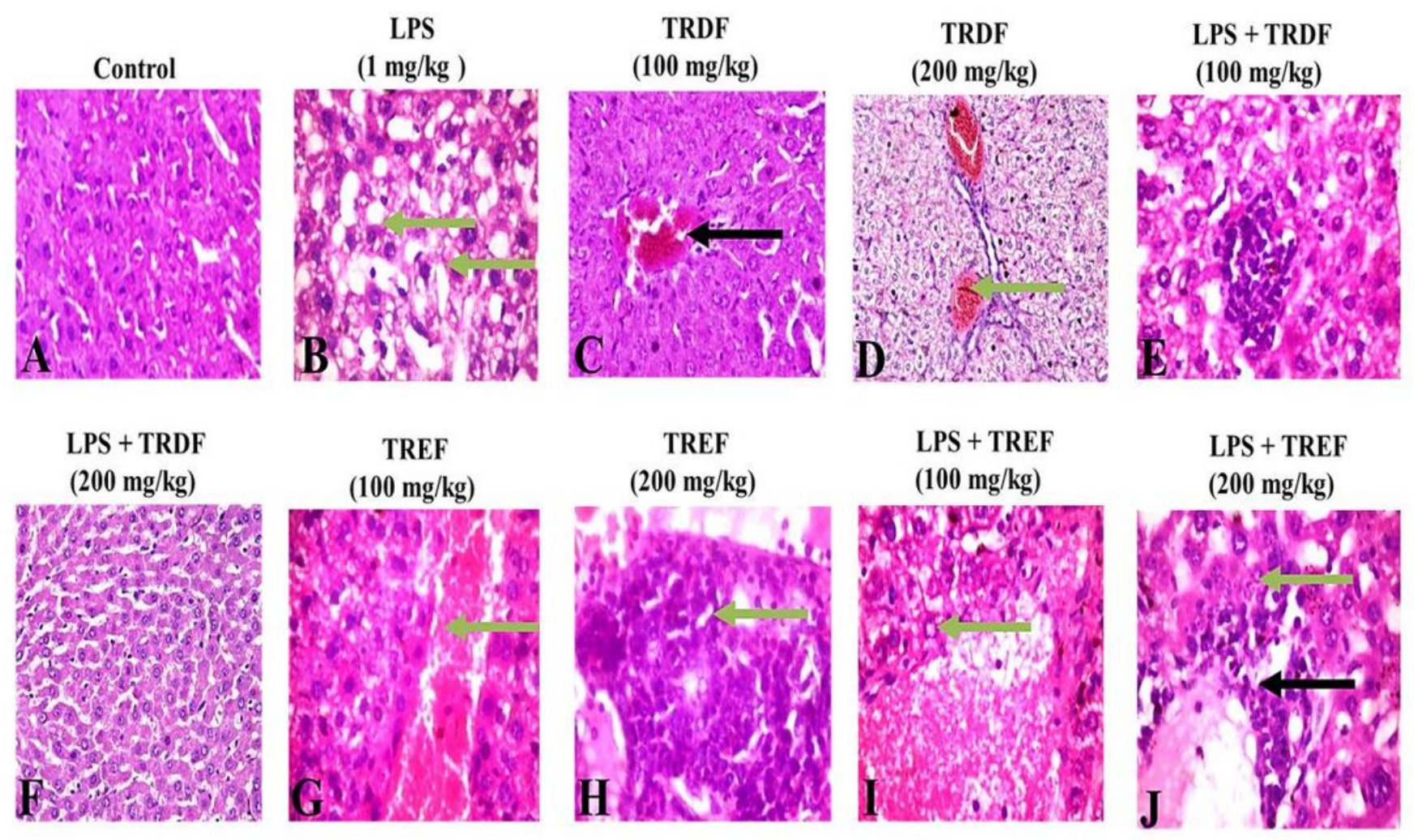

\section{Figure 5}

Hepatic histological sections stained with $\mathrm{H} \& \mathrm{E}$ at a magnification of 400x. (A) No visible significant lesion. (B) Plates show marked to severe disseminated micro/macro vesicular steatosis and marked periportal infiltration by inflammatory cells and mild disseminated infiltration of zone 2 by inflammatory cells and lymphoid nodule. (C) Moderate congestion of the portal vein seen (black arrow), some venules appear normal and not congested, the morphology of the hepatocytes appear normal and the sinusoids appear normal and not infiltrated. (D) Normal central venule and moderately congested portal vein, the parenchyma shows focal areas of haemorrhage, the morphology of the hepatocytes show cytoplasmic vacuolation. (E) Plate shows disseminated micro/macro vesicular steatosis and marked periportal infiltration by inflammatory cells and mild disseminated infiltration of zone 2 by inflammatory cells and lymphoid aggregate. (F) Normal central venule and moderately congested portal vein. The parenchyma shows focal areas of haemorrhage, the morphology of the hepatocytes show cytoplasmic vacuolation. (G) Plate shows disseminated congestion, extensive area of ground glass appearance and focal area of lymphoid aggregates. $(\mathrm{H})$ Plate shows congestion/thrombosis involving the veins and sinusoid, marked disseminated periportal infiltration by inflammatory cells and moderate to marked disseminated infiltration of zone 2. (I) Plate shows congestion/thrombosis, marked disseminated micro vesicular steatosis and very mild disseminated infiltration of zone 2 by inflammatory cells. (J) Plate shows moderate macro vesicular steatosis, moderate focal periportal infiltration by inflammatory cells and zone 2 shows extensive area of abscess 


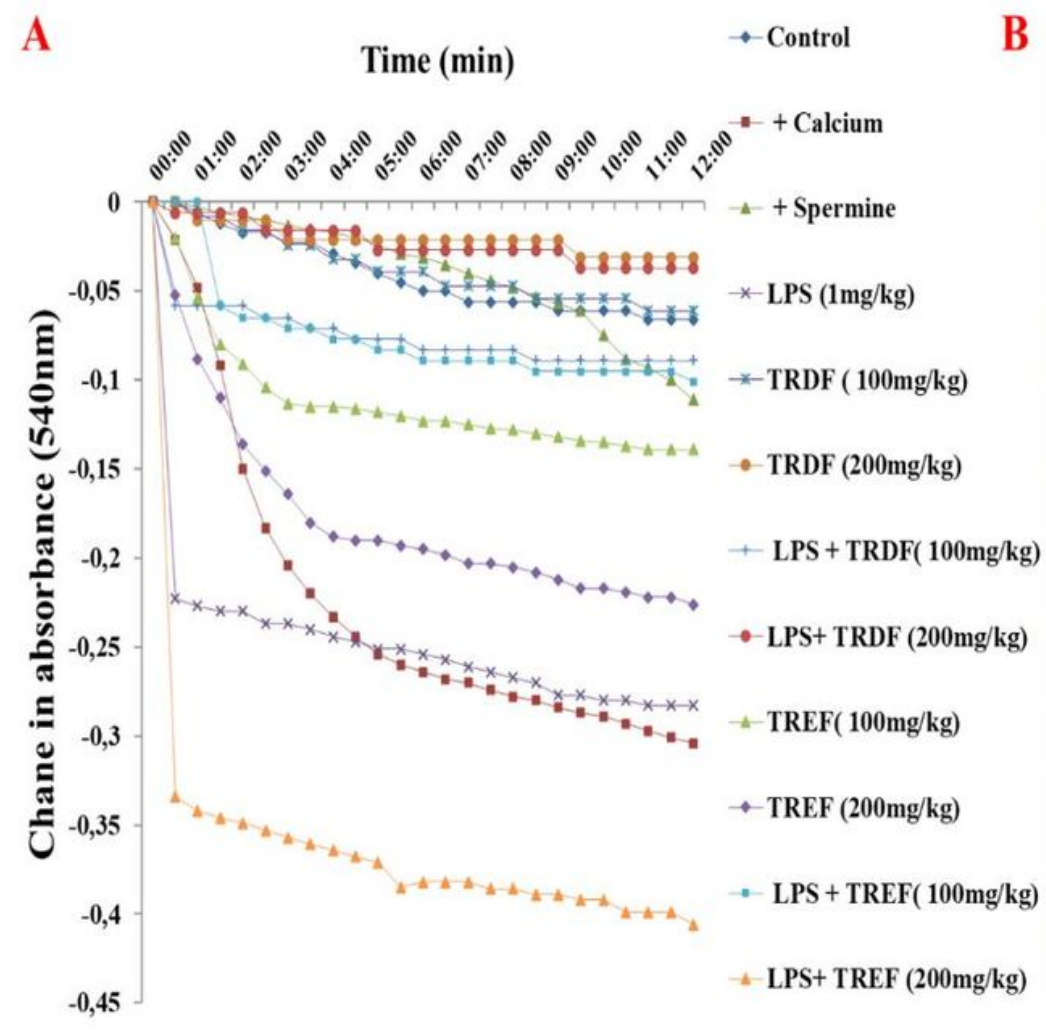

\begin{tabular}{|l|c|c|}
\hline Groups & $\begin{array}{c}\text { mPT pore fold } \\
\text { induction }\end{array}$ & $\begin{array}{c}\% \text { inhibition of } \\
\text { pore opening }\end{array}$ \\
\hline LPS (1 mg/kg) & 3.3 & - \\
\hline TRDF (100 mg/kg) & - & - \\
\hline TRDF (200 mg/kg ) & - & - \\
\hline LPS + TRDF (100 mg/kg) & - & $70.7 \%$ \\
\hline LPS + TRDF (200 mg/kg) & - & $87.8 \%$ \\
\hline TREF( 100 mg/kg) & 1.1 & - \\
\hline TREF (200 mg/kg) & 2.4 & - \\
\hline LPS + TREF(100 mg/kg) & - & $66.8 \%$ \\
\hline LPS + TREF (200 mg/kg) & 5.2 & - \\
\hline Calcium (TA) & 3.6 & - \\
\hline Spermine & - & \\
\hline
\end{tabular}

\section{Figure 6}

Representative profile of changes in absorbance of mitochondria isolated from livers of animals previously exposed to terpenes from F. mucoso in lipopolysaccharide (LPS)-treated mice. TRDF- TerpeneRich Dichloromethane Fraction of F.mucoso TREF- Terpene-Rich Ethyacetate Fraction of F.mucoso. *Typical data of one experiment are shown and similar results were obtained in at least three different preparations

A

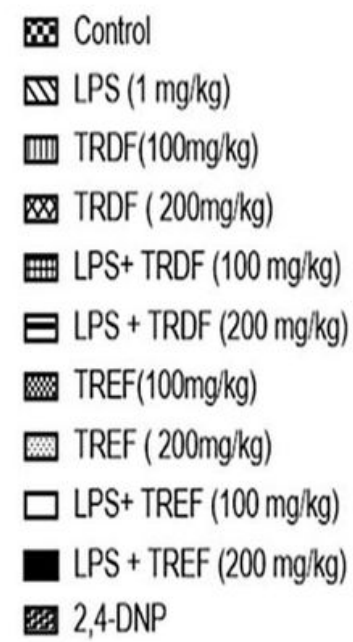

Mitochondrial ATPase activity

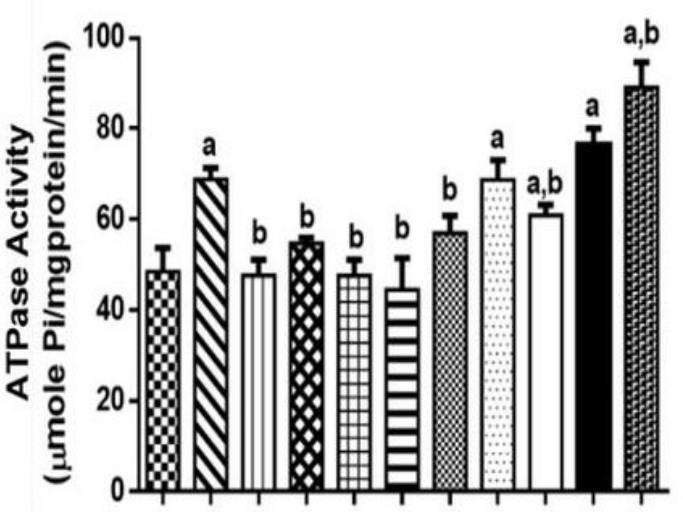

B Mitochondrial lipid peroxidation

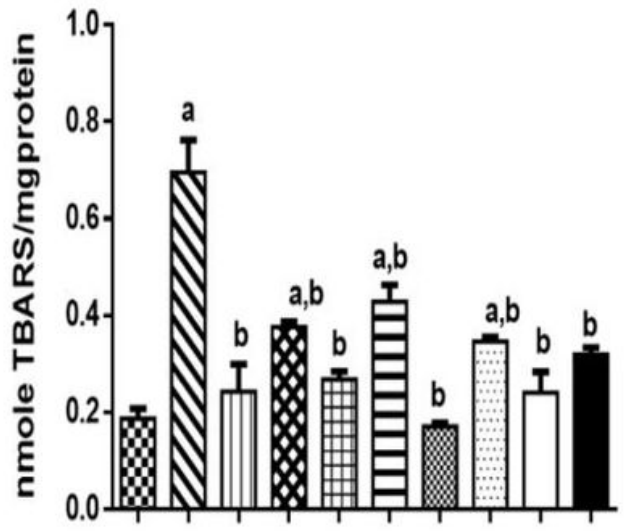


Mitochondrial ATPase (mATPase) activity and Degree of lipid peroxidation of mitochondria of livers of mice previously exposed to terpenes from F. mucoso in lipopolysaccharide (LPS)-treated mice (B). TRDFTerpene-Rich Dichloromethane Fraction of F. mucoso. TREF- Terpene-Rich Ethylacetate Fraction of F. mucoso. DNP-dinitrophenol. Values are expressed as Mean \pm Standard Error of Mean with 3 replicates per treatment group. Significant differences from the control are indicated by $a(p<0.05)$. Significant differences from the LPS-treated group indicated by $b(p<0.05)$.
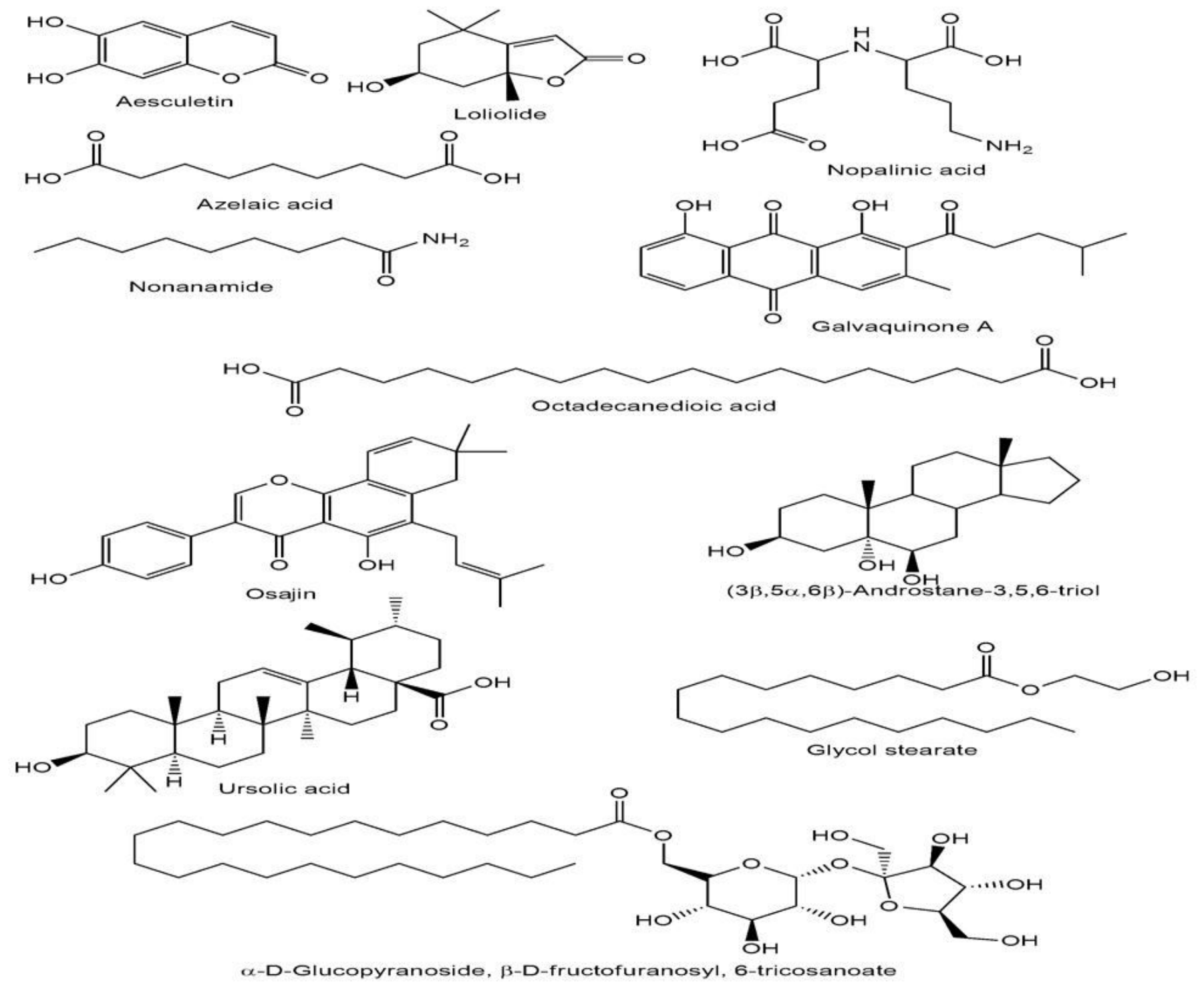

\section{Figure 8}

Chemical structures of identified TRDF metabolites 
<smiles>COc1cc(C(=O)O)ccc1O</smiles><smiles>CC1(C)C[C@H](O)C[C@@]2(C)OC(=O)C=C12</smiles>

Vanillic acid<smiles>CCCCC(=O)OCC(COC(=O)CCC)OC(=O)CCC</smiles>

Phoenixoside B<smiles>CC(C)=CCc1c(-c2ccc(O)cc2O)oc2c3c(cc(O)c12)C(C)(C)[C@@H](C)O3</smiles>

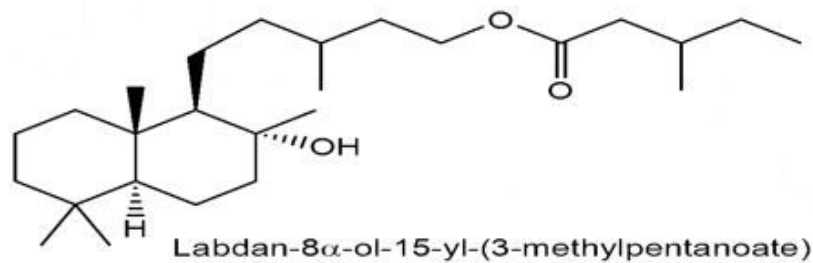<smiles>O=C(O)CCCCCCCC(=O)O</smiles>

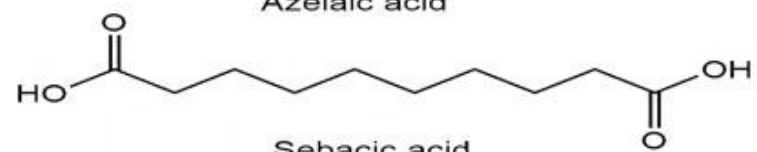

Sebacic acid<smiles>CC(O)C(O)C=CC(O)CCCCCCCC(=O)O</smiles>

Pinellic acid<smiles>C=CC(C)(C)c1c(O)cc(O)c2c(=O)c(CC=C(C)C)c(-c3ccc(O)cc3O)oc12</smiles><smiles>[R14]Cc1cc2c(C(C)(C)OC(C)=O)cc1C=C(C(C)(C)C=C)C(=O)O2</smiles>

Figure 9

Chemical structures of identified TREF metabolites 


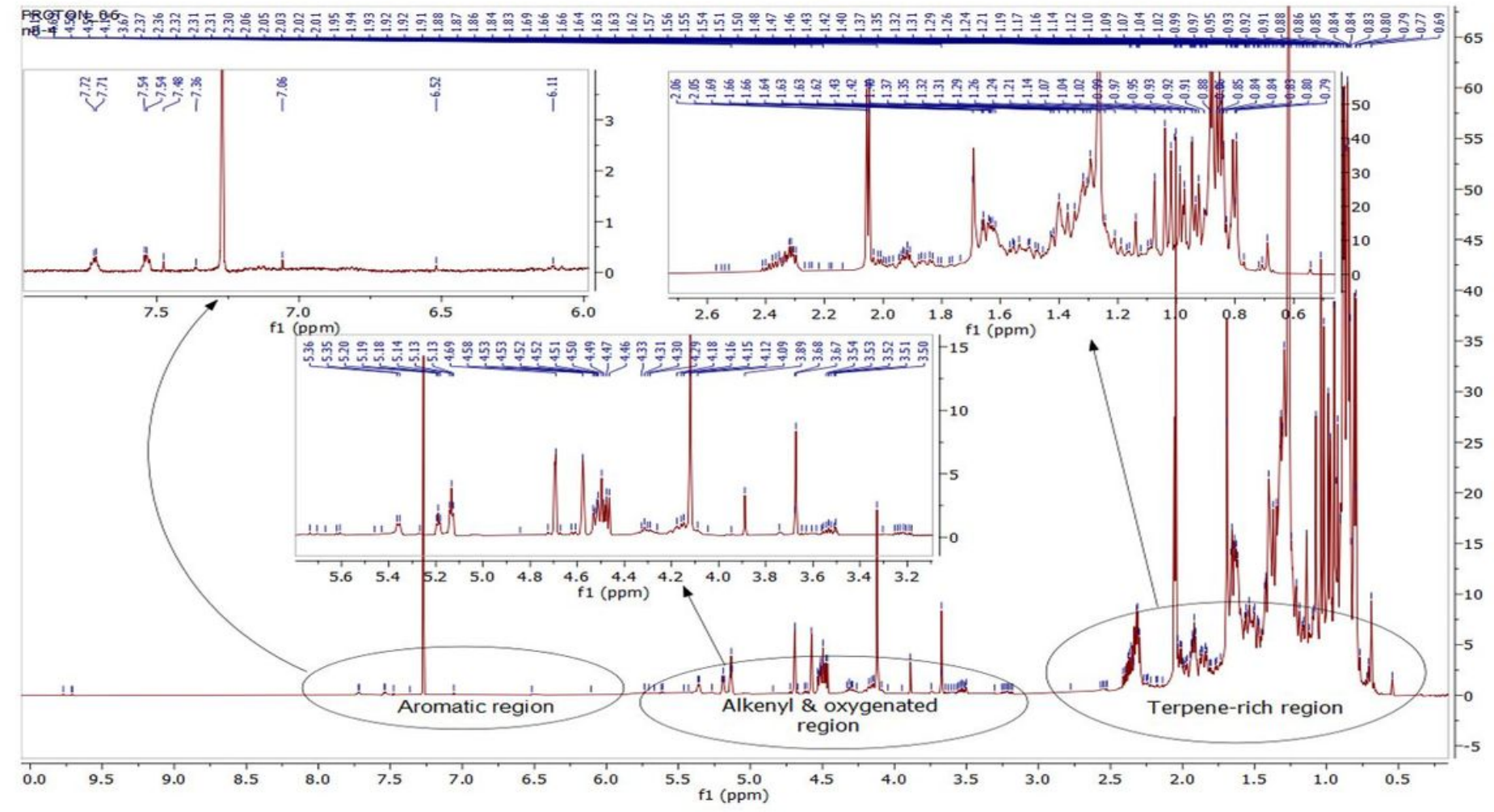

Figure 10

$1 \mathrm{H}$ NMR fingerprint of terpene-rich dichloromethane fraction (TRDF) 